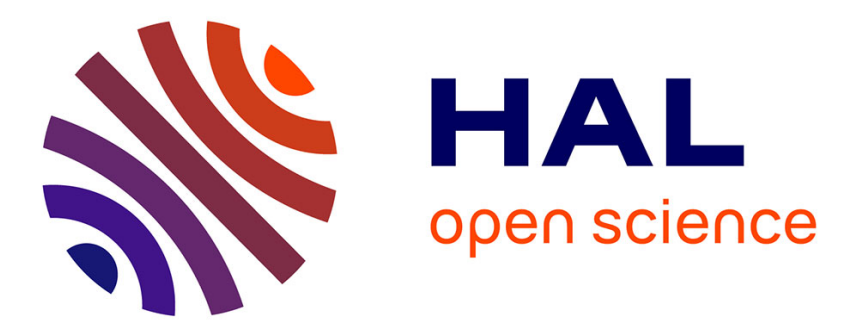

\title{
Butterfly-like Shape Liquid Crystals Based Fused-Thiophene as Unidimensional Ambipolar Organic Semiconductors with High Mobility
}

Tao Ma, Yu-jie Zhong, Hai-feng Wang, Ke-qing Zhao, Bi-qin Wang, Ping Hu, Hirosato Monobe, Bertrand Donnio

\section{To cite this version:}

Tao Ma, Yu-jie Zhong, Hai-feng Wang, Ke-qing Zhao, Bi-qin Wang, et al.. Butterfly-like Shape Liquid Crystals Based Fused-Thiophene as Unidimensional Ambipolar Organic Semiconductors with High Mobility. Chemistry - An Asian Journal, 2021, 16 (9), pp.1106-1117. 10.1002/asia.202100173 . hal-03404150

\author{
HAL Id: hal-03404150 \\ https://hal.science/hal-03404150
}

Submitted on 26 Oct 2021

HAL is a multi-disciplinary open access archive for the deposit and dissemination of scientific research documents, whether they are published or not. The documents may come from teaching and research institutions in France or abroad, or from public or private research centers.
L'archive ouverte pluridisciplinaire HAL, est destinée au dépôt et à la diffusion de documents scientifiques de niveau recherche, publiés ou non, émanant des établissements d'enseignement et de recherche français ou étrangers, des laboratoires publics ou privés. 


\section{Butterfly-like Shape Liquid Crystals Based Fused-Thiophene as Unidimensional Ambipolar Organic Semiconductors with High Mobility}

Tao Ma,[a] Yu-Jie Zhong,[a] Hai-Feng Wang,[a] Ke-Qing Zhao, *[a] Bi-Qin Wang,[a] Ping Hu,[a] Hirosato Monobe, ${ }^{*}[\mathrm{~b}]$ and Bertrand Donnio*[c]

Cite as Chem. Asian J. 2021, 16, 1106-1117

Publication Date: March 11, 2021

https://doi.org/10.1002/asia.202100173

Butterfly-like mesogens based on benzodithiophene, benzodithiophene-4,8-dione and cyclopentadithiophen-4-one core moieties were efficiently synthesized by the Suzuki-Miyaura/Scholl reactions' tandem. Depending on the core nature and radial aliphatic chains number, they selforganize into columnar hexagonal mesophase, possess solvent-gelling ability, emit light in the visible range, and display hole-transport performances. In particular, the mesogen with benzodithiophen-4,8dione core shows ambipolar charge carrier transport with both high electron and hole mobility values.

Abstract: Mesomorphous butterfly-like shape molecules based on benzodithiophene, benzodithiophene-4,8-dione and cyclopentadithiophen-4-one core moieties were efficiently synthesized by the Suzuki-Miyaura coupling and Scholl oxidative cyclodehydrogenation reactions' tandem. Most of the butterfly molecules spontaneously selforganize into columnar hexagonal mesophase. The electron-deficient systems possess strong solvent-gelling ability but are not luminescent, whereas the electron-rich terms do not form gels but strongly emit light between 400 and 600

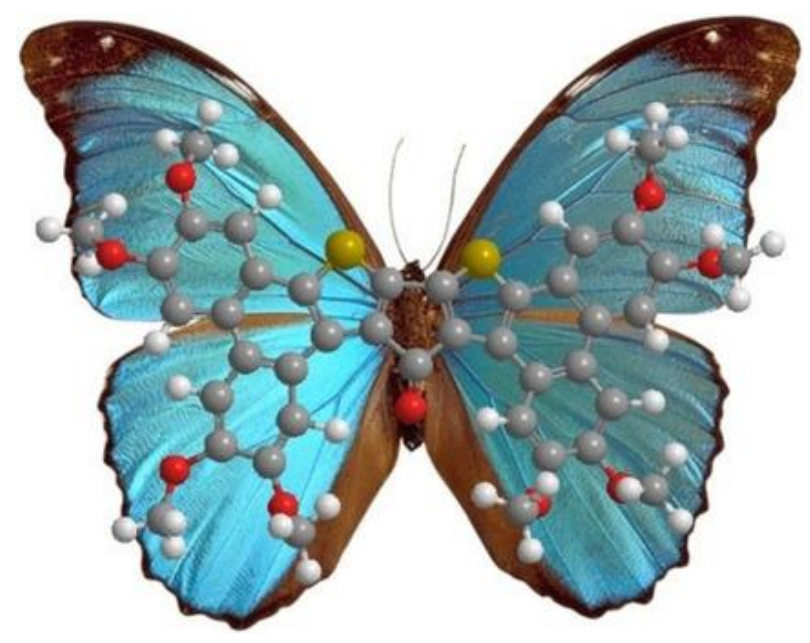
$\mathrm{nm}$. The charge carrier mobility was also measured by time-of-flight transient photocurrent technique in the mesophases for some of the compounds. They display hole-transport performances with positive charge mobility in the $10^{-3} \mathrm{~cm}^{-2} \mathrm{~V}^{-1} \mathrm{~s}^{-1}$ range, consistent with the high degree of ordering and stability of the columnar superstructures. In particular, the mesogen with a benzodithiophen-4,8-dione core shows ambipolar charge carrier transport with both high electron $\left(\mu_{\mathrm{e}}=6.6 \times 10^{-3} \mathrm{~cm}^{-2} \mathrm{~V}^{-1} \mathrm{~s}^{-1}\right)$ and hole $\left(\mu_{\mathrm{h}}=4.5 \times 10^{-3} \mathrm{~cm}^{-2} \mathrm{~V}^{-1} \mathrm{~s}^{-1}\right)$ mobility values. 


\section{Introduction}

In recent decades, great advances in the chemistry of carbon-and heteroatom-based $\pi$-conjugated systems have contributed substantially to the emergence of organic electronics and optoelectronics research domains, [1] as evidenced by the large quantity of synthesized semiconducting molecular and macromolecular systems for a variety of technological and medical applications. Among the numerous synthetic methods now available in the chemistry of conjugated systems toolbox, Suzuki-Miyaura cross-coupling[2] and Scholl aromatic oxidative cyclo-dehydrogenation[3] are two of the very powerful methodologies and now used mostly ubiquitously in the construction of 2-dimensional nanographenes and polycyclic heteroatomic semiconducting materials. $[3,4,5] \pi$-Conjugated liquid crystals[6] ( $\pi$-LCs) are versatile, everlasting hot-topic of functional materials. They are able to spontaneously selforganize into fluid mesophases of low dimensionality, [7] possess outstanding electronic properties, and are in principle inexpensive to process in solution to form aligned, self-healing films, of interest in many potential sensorand display-based industrial applications. In particular, conjugated discotic LCs $(\pi$-DLCs),[8] consisting of a discotic polycyclic aromatic hydrocarbon (PAH) core structure chemically bonded to at least six peripheral alkyl chains, are being extensively studied as possible one-dimensional organic semiconductors.[9] Such $\pi$-DLCs indeed spontaneously self-assemble into infinite onedimensional columns by face-to-face $\pi-\pi$ stacking, thus providing unique molecular conductive channels for electrons hopping, insulated from each other by an aliphatic continuum.[10] As a type of soft, dynamic, anisotropic electronic conductors, $\pi$-DLCs appear as promising self-organized (macro) molecular semiconductors for applications in electronic devices such as organic field effect transistors (OFETs), $[8,9,10]$ organic light-emitting diodes (OLEDs)[11] and organic solar cells (OSCs).[12] Columnar mesophases are primarily obtained by the self-assembly of highly symmetrical disc-shaped molecules such as the archetypical polycyclic aromatics of the benzoid family e.g. triphenylenes,[13] hexabenzocoronenes,[14] or the heterocyclic porphyrine and phthalocycanine derivatives.[15,16] They can also be induced by other molecular systems with shapes deviating substantially from a disc such as, just to cite but a few examples, tapered,[17] polycatenar,[18] star-[19] and bent-shaped[20] mesogens. However, the former systems possess generally higher charge carrier transport properties[21] than in columns made of these non-discoid mesogens,[22] whose small size of their aromatic cores with limited conjugation and $\pi$-overlap, associated with rotational symmetry around the long axis, may be detrimental to the optimization of molecular interactions and stacking. To improve the mobility of charges in discotic systems, research attentions have focused on modifying the periphery (nature and type of chains) and/or changing the molecular-core nature, symmetry and size.[10,23] Beside disc-like molecules, there have been recently few reports on board-like molecules, pseudo-discs also possessing large extended $\pi$-systems and being able to stack, exhibiting high electronic charge transport mobility competing with those from conventional DLCs.[24] Structurally related butterfly-like shape molecules specifically made from fused-thiophene aromatics also stack up into columnar mesophases, and were found to exhibit attractive optical properties as well as enhanced electron-conducting properties.[25-27] Sulphur-containing heterocyclic aromatics are electron-rich and extended $\pi$-orbitals benefit largely to enhanced $\pi-\pi$ stacking, and charges hop smoothly among positionally ordered molecules.[28-30] Furthermore, rotational freedom and conformational flexibility may lead to lower mesophases' stability and narrower temperature ranges,[25,31] while conformationally fixed $\pi$-conjugated scaffolds display in contrast very stable columnar mesophases with high phase transition temperatures, that can act as high temperature organic semiconductors in addition to promote self-assembly in supramolecular organic gels (Figure 1).[27] Lately, we have successfully combined both the Suzuki-Miyaura coupling and the Scholl cyclo-dehydrogenation model reactions to synthesize, in few efficient steps, several new mesogens yielding columnar liquid crystalline semiconductors.[25-27,31] Our exploration of original molecular systems and the 
understanding of structure-activity relationships lent us to construct novel butterfly-shaped molecules based on fused-thiophene with different $\pi$-extended scaffolds (Figure 1). Chemical design of organic semiconductors is an important research subject, as it can help tuning the materials light absorption and emission, their stability in ambient condition, and the semiconducting $\mathrm{p}$ - or n-type, or both (ambipolar) character. For this study, three different electroactive cores were considered, namely the electron-rich benzodithiophene (BDT), and both electron-deficient benzodithiophene-4,8-dione (BDTD) and cyclopentadithiophen-4-one (CDTO), respectively. The target diphenanthrene-fused compounds described here were obtained in rather satisfying overall yields by this effective tandem reactions methodology. The results show that, depending on the nature of the core and chains, these lipophilic butterfly-shaped fused-thiophene molecules, both before and after annulation, self-organize into supramolecular columnar mesophases with high thermal stability and wide mesomorphic ranges, form fibrillary gels in various solvents, are luminescent and display high charge carrier mobility values.

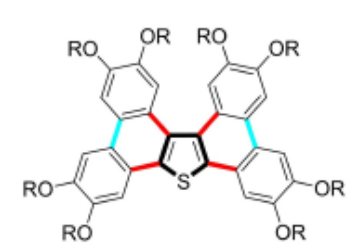

DT

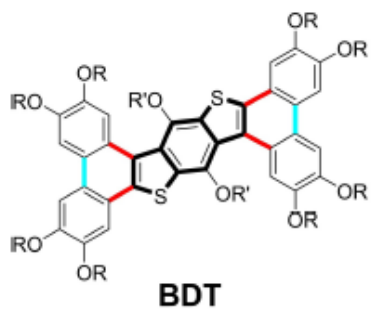

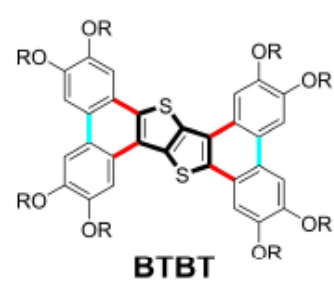

BTBT

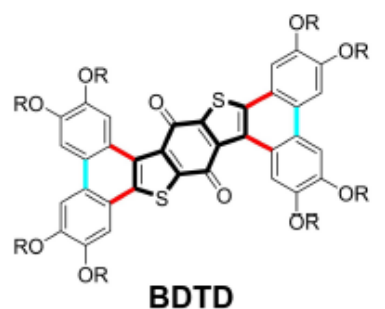

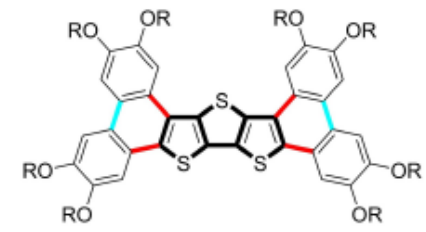

DTT

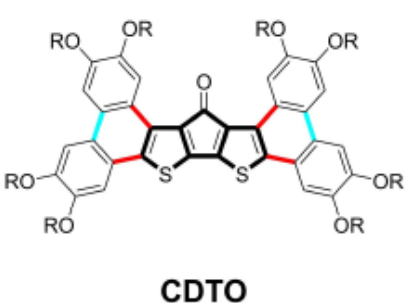

Figure 1. Board-like and butterfly-shaped fused-thiophene columnar liquid crystalline semiconductors synthesized by successive Suzuki (bonds in red) and Scholl (bonds in blue) reactions: DT, [25] BTBT, [26] DTT, [27] BDT, BDTD and CDTO, this work ( $\mathrm{R}$ and $\mathrm{R}^{\prime}$ are alkyl chains, $\mathrm{C}_{n} \mathrm{H}_{2 n+1}$ ).

\section{Results and Discussion}

Design, synthesis and characterization The extension of aromatic cores and conjugation towards nanographene-like discoid structures can result in more efficient $\pi-\pi$ stacking that helps stabilizing columnar mesophases, and thus promoting high charge carrier mobility. $[10,12,31]$ Furthermore, the $S$ atom has extended p-orbitals and larger atomic radius, and when piled face-to-face, sulphurcontaining aromatic cycles (usually fused thiophenes) possess strong intermolecular interactions. Such interactions between disc-shaped aromatic mesogens can additionally be tuned by the number of alkyl groups chemically attached to the periphery of the rigid core or/and by specific polar groups inserted within the central aromatic core.[32-34] We report in this work a robust and efficient synthesis of several new series of columnar mesophase semiconductors having a butterfly shape, and the investigation of the impact of electrondeficient/rich cores and length and number of alkyl chains on their photophysical and electronic properties. The target butterfly-shaped molecules were obtained by conventional $\mathrm{Pd}\left(\mathrm{PPh}_{3}\right)_{4}$-catalyzed Suzuki-Miyaura cross-coupling and intramolecular Scholl $\mathrm{FeCl}_{3}-$ catalyzed aromatic oxidative reactions, from commercially available reagents. In brief, the bromation of various accessible dithiophene-containing polyaromatic cores e.g. 4,8-dialkoxybenzo[1,2- $b: 4,5-$ $b^{\prime}$ ]dithiophene (BDT), benzo[1,2-b:4,5- $\left.b^{\prime}\right]$ dithiophene-4,8-dione (BDTD) and 4H-cyclopenta[2,1- $b: 3,4-$ 
$b^{\prime}$ ]dithiophen-4-one (CDTO) respectively yielded the corresponding tetrabromo-substituted dithiophene arenes (B1-4, Scheme S1). Four identical 2-(3,4-bis(alkyloxy) phenyl)-4,4,5,5-tetramethyl1,3,2-dioxaborolane fragments (6a-6e, Scheme 1 ) were then bonded to these various bromide-rich cores by the Suzuki-Miyaura coupling reaction to lead the corresponding tetraaryl dithieno-arene derivatives (1a-4e, Scheme 1). The desired annulated diphenanthrene-fused derivatives (Scheme 1) were obtained by direct intramolecular $\mathrm{FeCl}_{3}$ - oxidative cyclo-dehydrogenation reaction. The high efficiency of the intramolecular oxidative coupling is to be emphasized: four $\mathrm{C}-\mathrm{H}$ bonds were cleaved and two $\mathrm{C}-\mathrm{C}$ bonds formed during the one-pot synthesis of the diphenanthrene derivatives, without the formation of regio-isomers or other side products, as confirmed, when applicable, by NMR. Lipophilic compounds BDTa-c, with ten or more diverging chains, exhibited excellent solubility in organic solvents, and were solely purified by silica gel column chromatography. However, the ketone derivatives BDTDd and CDTOc-e with 8 peripheral alkyls chains showed lower solubility in organic solvents and could only be purified by crystallization in dry hot toluene. All the new precursors and annulated compounds but the poorly soluble diphenanthrene derivatives BDTDd and CDTOc-e were characterized by ${ }^{1} \mathrm{H}$ and ${ }^{13} \mathrm{C}$ NMR spectroscopy (Figures S17-S30). In the case of the highly soluble BDTa-c compounds, the cyclo-dehydrogenation was neatly confirmed by ${ }^{1} \mathrm{H}$ NMR: they provided much simpler spectra than their tetraaryl parents, consisting of four well-defined singlet signals in the 7-10 ppm range corresponding each to the remaining four different types of aromatic protons of the $\pi$ conjugated core. All the target diphenanthrenes were further characterized by high resolution mass spectra (Figures S31-S37) and elemental analysis. These analyses were in good agreement with the proposed chemical structures.
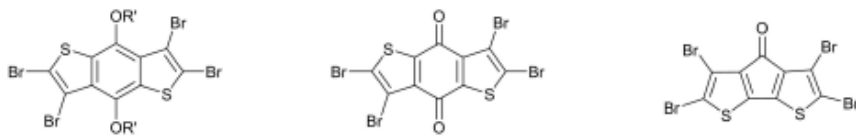

B1: $\mathrm{R}^{\prime}=\mathrm{CH}_{2} \mathrm{CH}_{\left(\mathrm{C}_{0} \mathrm{H}_{13}\right)\left(\mathrm{C}_{8} \mathrm{H}_{17}\right)}$
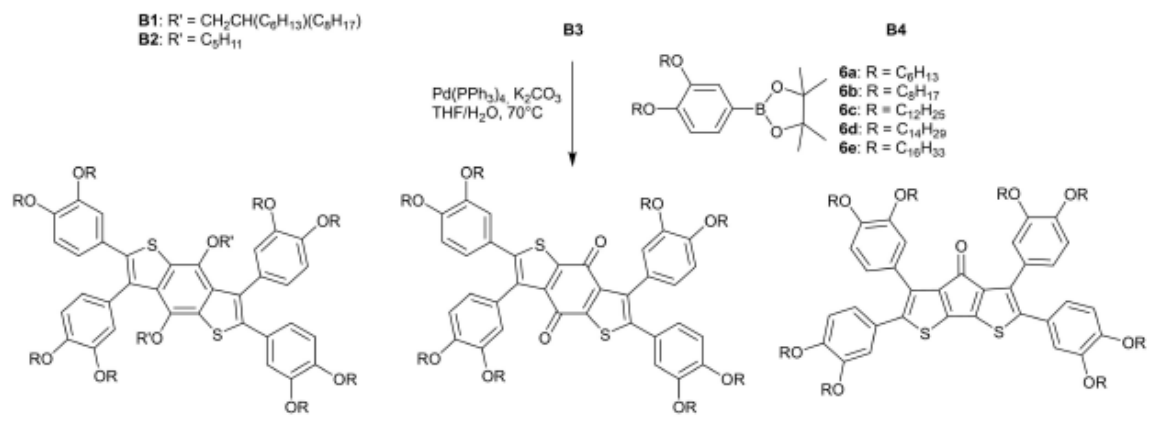

1a: R $=\mathrm{C}_{6} \mathrm{H}_{13}, \mathrm{R}^{\prime}=\mathrm{CH}_{2} \mathrm{CH}\left(\mathrm{C}_{6} \mathrm{H}_{13}\right)\left(\mathrm{C}_{8} \mathrm{H}_{17}\right)$

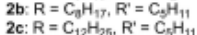

3d: $R=C_{14} H_{28}$
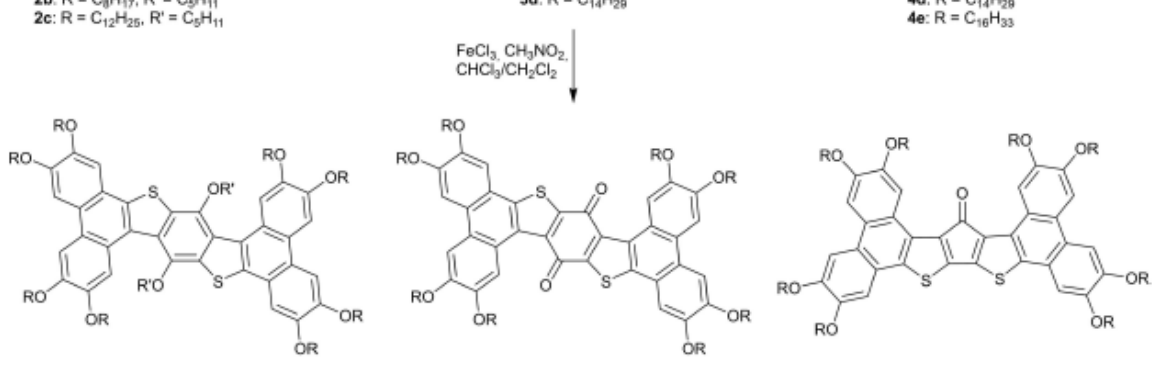

BDTa: $\mathrm{R}=\mathrm{C}_{6} \mathrm{H}_{13}, \mathrm{R}^{\prime}=\mathrm{CH}_{2} \mathrm{CH}\left(\mathrm{C}_{6} \mathrm{H}_{13}\right)\left(\mathrm{C}_{8} \mathrm{H}_{17}\right)$ BDTb: $R=\mathrm{C}_{8} \mathrm{H}_{17}, \mathrm{R}^{\prime}=\mathrm{C}_{5} \mathrm{H}_{11}$
BDTC: $\mathrm{R}=\mathrm{C}_{12} \mathrm{H}_{25}, \mathrm{R}^{\prime}=\mathrm{C}_{5} \mathrm{H}_{11}$

BDTDd: $\mathrm{R}=\mathrm{C}_{14} \mathrm{H}_{20}$

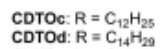

CDTOd: $\mathrm{R}=\mathrm{C}_{12} \mathrm{C}_{29}$
CDTOe $\mathrm{R}=\mathrm{C}_{13} \mathrm{H}_{33}$

4c: $\mathrm{R}=\mathrm{C}_{12} \mathrm{H}_{25}$
4d: $\mathrm{R}=\mathrm{C}_{14} \mathrm{H}_{20}$$$
\text { OR }
$$

CDTOe: $\mathrm{R}=\mathrm{C}_{10} \mathrm{H}$

Scheme 1. General synthetic scheme and nomenclature of the various tetraaryls and corresponding diphenanthrene butterfly-shaped fused-thiophene LC semiconductors: 4,8-dialkoxybenzo[1,2-b:4,5$b^{\prime}$ ]dithiophene (BDT) core for 1a-2c and BDTa-c; benzo[1,2-b:4,5- $b^{\prime}$ ]dithiophene-4,8-dione (BDTD) core for 3d and BDTDd; $4 \mathrm{H}$-cyclopenta[2,1-b:3,4- $b^{\prime}$ ]dithiophen-4-one (CDTO) core for $\mathbf{4 c - e}$ and CDTOc-e. 
Thermal and structural properties The good chemical stability of the precursory tetraaryls and diphenanthrenes was primarily confirmed during their isolation, purification and characterization. Thermal gravimetrical analysis (TGA) (Figure S1, Table S1) revealed that the decomposition temperatures, $T_{\mathrm{dec}}$, are higher than $300^{\circ} \mathrm{C}$ for essentially all of them, with no or little effect of the core stiffening upon annulation or chains topology and length; the highest decomposition onset was as high as $395^{\circ} \mathrm{C}$, probing the excellent thermal stability of these fused-thiophene molecules. The nature of the core slightly affects the thermal stability. For the first series of compounds based on the BDT core (1a-2c and BDTa-c), congested by two central protruding side chains, $\mathrm{T}_{\text {dec }}$ lied in the range between 311 to $341^{\circ} \mathrm{C}$, whereas those of the compounds with BDTD and CDTO cores were increased by ca 45$50^{\circ} \mathrm{C}$. The lower thermal stability of the BDT derivatives may be related to the presence of the two central protruding chains. Actually, a two-step decomposition process was observed for these derivatives: a first decomposition event at ca. $300^{\circ} \mathrm{C}$, which could be attributed to thermal dealkylation of the central benzene ring, which was followed by a second weight-loss occurring slightly below $400^{\circ} \mathrm{C}$, fully consistent with the onset of the dealkylation of the eight remaining alkoxy groups, as perfectly superimposed with the decomposition curves of the BDTD and CDTO compounds.

The liquid crystal properties of the precursors, $1 \mathbf{a}-\mathbf{4 e}$, and of the diphenanthrene derivatives were first studied by polarized optical microscopy (POM, Figures 2 and S2) and differential scanning calorimetry (DSC, Figure S3, Table S2): 9 compounds out of the 14 synthesized thiophene-containing derivatives (3d/4c-e, BDTc/BDTDd/CDTOc-e) are mesomorphous. Representative POM textures revealed birefringent pseudo-focal conic domains (Figure 2a,c) and large area homeotropic domains with long linear defects (Figure $2 b, d-f$ ), both features pointing to Col $_{\text {hex }}$ mesophases.

The combination of 10 or 12 surrounding alkyl chain fragments and $4 \sigma$-bonded phenyl rings with free rotational freedom within the small electron-rich aromatic BDT core, i. e. compounds $\mathbf{1 a}, \mathbf{2} \mathbf{b}$ and $\mathbf{2 c}$, was obviously detrimental to the induction of mesomorphism, as all melted in the isotropic liquid below $100^{\circ} \mathrm{C}$ without showing any mesophase; furthermore, crystallization occurred with some supercooling effect (DSC). Modifying the electronic property of the central aromatic core from BDT to the electron-deficient BDTD and CDTO led to the systematic induction of mesomorphism: all the tetraaryls 3d/ 4c-e exhibit a Col hex mesophase, as easily recognized by POM (growing birefringent monodomains and homeotropic zones, Figure 2a,b). Tetra-aryl 3d, possessing two central carbonyl groups in the core, displays a broad mesophase between 42 to $167^{\circ} \mathrm{C}$, whereas the clearing temperatures of the compounds with only one carbonyl group, series 4 , drastically dropped down to ca. $110^{\circ} \mathrm{C}\left(108^{\circ} \mathrm{C}\right.$ for $\mathbf{4} \mathbf{d}$ with same chain-length as $\mathbf{3 d}$ ), likely due to the slighter deviation from planarity as compared to $\mathbf{3 d}$ (DFT, Table S11). The first two homologues of this series (4c, $\mathbf{4 d}$ ) appeared to show the so-called double-clearing behaviour, a rare phenomenon in low-molecular weight LCs though frequently observed in oligomeric and polymeric LCs. This singularity, later confirmed by S/WAXS experiments (see below), will not be further discussed as not relevant in this study, but may be due to the high flexibility of the four pending aryl groups freezing the whole molecule in specific conformations, leading first to the melting of the hexagonal lattice into a first isotropic liquid (no birefringence detected by POM), I', made of short-range, uncorrelated, columnar aggregates, followed by their complete destruction and isotropization into the second isotropic liquid, I. This behaviour is progressively lost with chain-length increase. The observation of mesomorphism in these tetraaryl thiophene molecules suggests that the electron-deficient core strongly promotes molecular stacking and columnar mesophases' formation, similarly to some other structurally related systems reported in the literature.[35,36] Recall in particular that the analogous dithienothiophene derivatives DTT, [27] whose $\mathrm{S}$-atom is replaced by the carbonyl group (4d), exhibits only a monotropic and over a narrower mesophase range (from 67 to $26^{\circ} \mathrm{C}$ on cooling). 


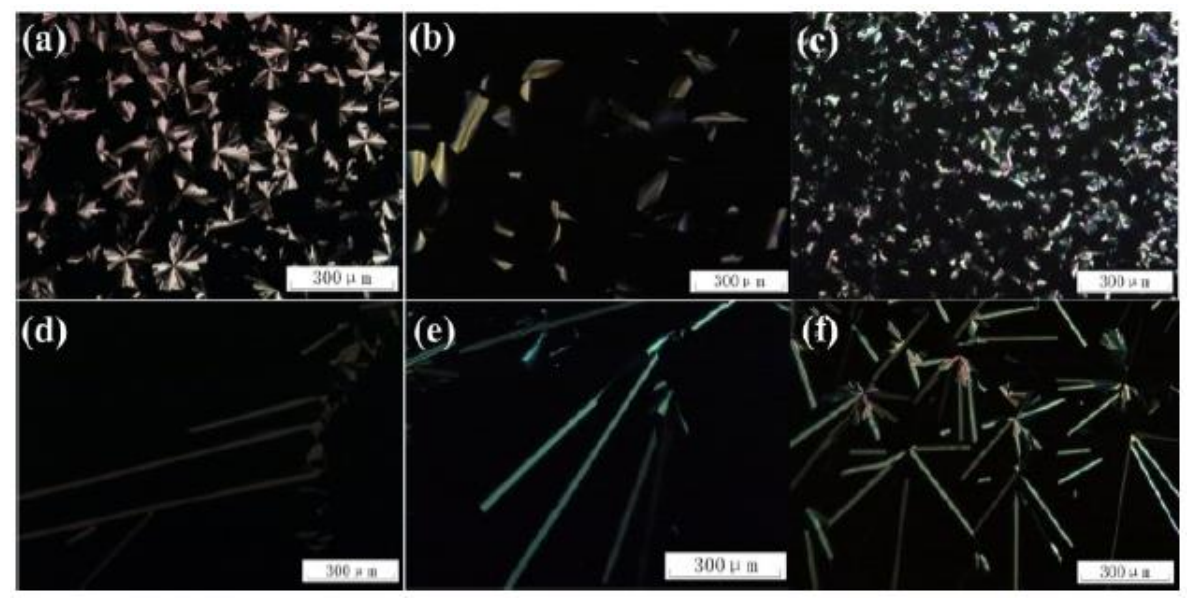

Figure 2. Representative polarized optical photomicrographs of (a): $\mathbf{3 d}$ at $100^{\circ} \mathrm{C}$; (b): $\mathbf{4 d}$ at $85{ }^{\circ} \mathrm{C}$; (c): BDTc at $50^{\circ} \mathrm{C}$; (d): $\mathbf{B D T D d}$ at $235^{\circ} \mathrm{C}$; (e): CDTOd at $140^{\circ} \mathrm{C}$; (f): CDTOe at $127^{\circ} \mathrm{C}$, on cooling from isotropic liquid with rate of $5^{\circ} \mathrm{C} / \mathrm{min}$. Additional POM images in Figure S2.

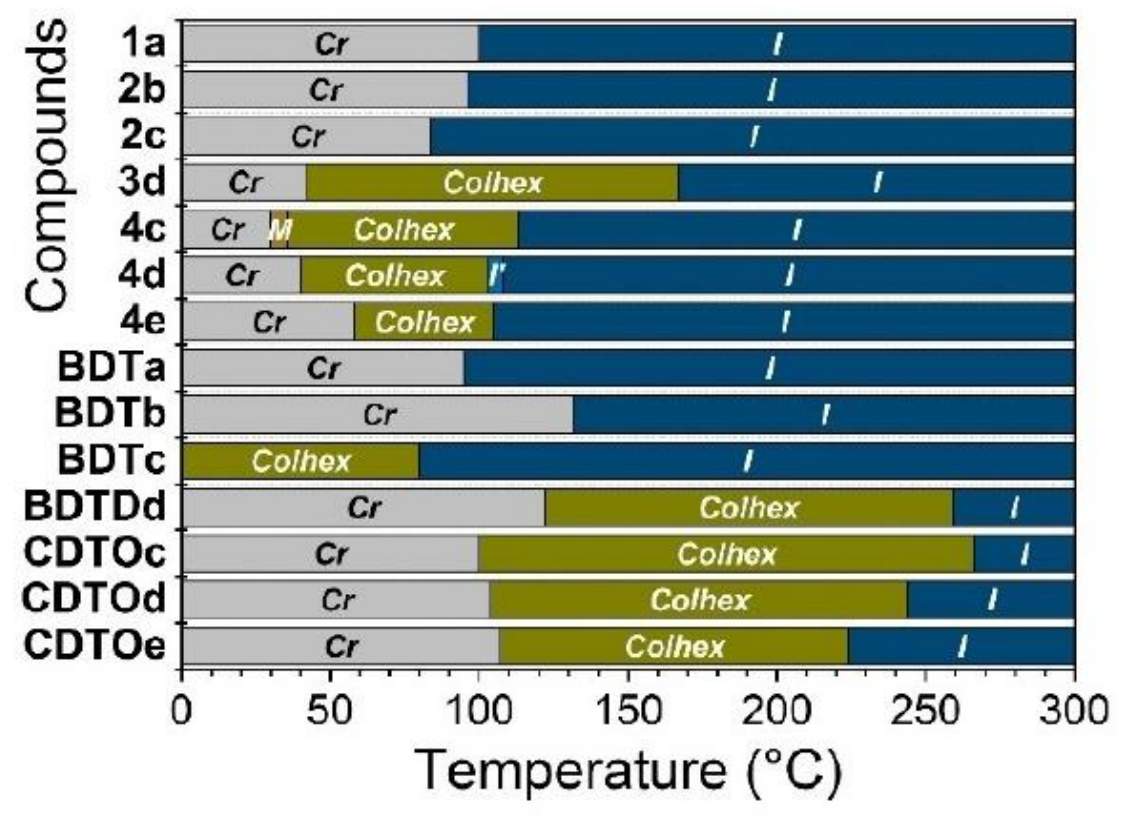

Figure 3. Thermal and thermotropic mesophase diagram of 1a-4e and corresponding diphenanthrenes (DSC curves are shown in Figure S3, and numerical data gathered in Table S2). Cr: crystal phase; I, I': isotropic liquids(see text); M: pre-organized phase; Colhex: hexagonal columnar phase.

The thermal and self-organizational behaviour change dramatically after oxidative aromatic cyclization (Scholl reaction). The resulting diphenanthrene molecules exhibit pronounced one-dimensional columnar stacking, as shown in the optical textures by the presence of long linear defect features and large homeotropic zones (Figures $2 \mathrm{c}-\mathrm{f}$ and $\mathrm{S} 2$ ), and broader mesophase ranges significantly shifted to higher temperatures compared to their non-annulated counterparts. Specifically, for the electron-

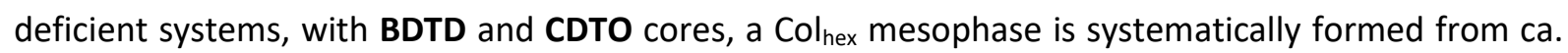
122 to $259^{\circ} \mathrm{C}$, and from ca. 100 to 266,244 and $224^{\circ} \mathrm{C}$, respectively, likely due to both core stiffening (MD, DFT- Figures S38-S40, Table S11) and conjugation extension, thus to enhanced intermolecular interactions (stronger $\pi-\pi$ stacking and electrostatic interactions). The maximum mesophase extension of the CDTO series is observed for the dodecyl homolog (Figure 3). As for the diphenanthrenes with 
the electron-rich BDT core, mesomorphism was induced only for the derivative with the longer linear chains, showing an enantiotropic room temperature Col hex mesophase $\left(-13 \mathrm{Col}\right.$ hex $\left.80^{\circ} \mathrm{C}\right)$. So mesomorphism in this system clearly depends on the balance between the lateral chains' length to compensate for the detrimental role played by the two central chains. Rigidity is thus not the sole criteria for mesomorphism induction.
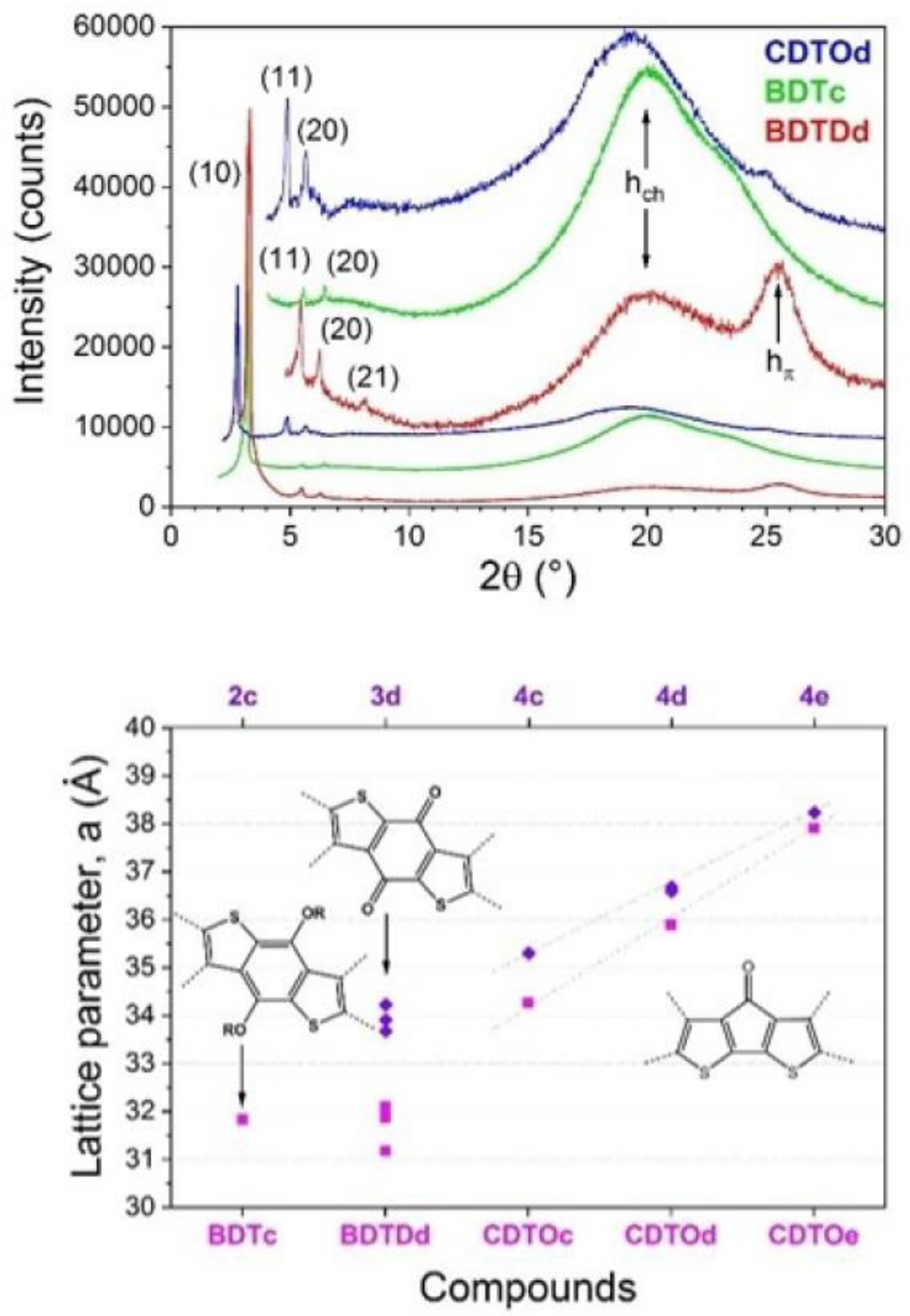

Figure 4. Top: Small-angle X-ray scattering (S/WAXS) patterns of mesophases for the three representative diphenanthrene mesogens (recorded on cooling at various temperatures); Bottom: Evolution of the hexagonal lattice parameter with structure and temperature.

The assignment of the Colhex mesophase made by POM was unambiguously confirmed by S/WAXS (small- and wide-angle X-ray scattering) measurements. The X-ray patterns of both tetraaryls and annulated mesomorphous compounds, recorded at various temperatures in the mesophases (Figures 4 and S4), display indistinctly the characteristic scattering signals in the wide-angle range, $h_{c h}$ and $h_{\pi}$, emerging respectively from lateral distances between molten chains $\left(h_{c h} \sim 4.3-4.6 \AA\right)$ and from the 
stacking between the juxtaposed mesogenic cores $\left(h_{\pi} \sim 3.3-3.7 \AA\right)$; let us remark that this latter signal is present for most compounds but with a variable intensity, indicative of the more or less extension of the stacking ordering range. In the small-angle range, the patterns exhibit an intense, first-order reflection (10), and two or three weaker, higher-order reflections, indexed as (11), (20) and (21) of a hexagonal lattice, respectively, according to spacing ratios of 1:V3:V4:V7 (Figure 4). The presence of several sharp reflections $(h k)$ reveals the long-range ordering of the two-dimensional lattice and of well-defined interfaces characterizing the efficient segregation between the non-miscible parts, i. e. the supramolecular columns, resulting from the regular stacking of the mesogenic cores localized at the nodes of the lattice, and the molten aliphatic continuum between the columns.

\begin{tabular}{|c|c|c|c|c|c|c|c|c|c|c|c|c|c|}
\hline Cpds & $\begin{array}{l}\mathrm{T}^{[\mathrm{a}]} \\
{\left[{ }^{\circ} \mathrm{C}\right]}\end{array}$ & $\begin{array}{l}V_{\mathrm{mol}}^{[\mathrm{b}]} \\
{\left[\AA^{3}\right]}\end{array}$ & $\begin{array}{l}\rho^{[\mathrm{b}]} \\
{\left[\mathrm{g} \mathrm{cm}^{-3}\right]}\end{array}$ & $\chi_{c h}{ }^{[c]}$ & $\begin{array}{l}\mathrm{a}^{[\mathrm{d}]} \\
{[\AA \AA]}\end{array}$ & $\begin{array}{l}\mathrm{A}[\mathrm{Z}]^{[\mathrm{d}]} \\
{\left[\AA^{2}\right]}\end{array}$ & $\begin{array}{l}\mathrm{h}_{\text {mol }}^{\text {[e] }} \\
{[\hat{\AA}]}\end{array}$ & $\begin{array}{l}\mathrm{h}_{\pi}^{[\mathrm{e}]} \\
{[\AA \AA]}\end{array}$ & $\begin{array}{l}\psi^{[f]} \\
{\left[{ }^{\circ}\right]}\end{array}$ & $\begin{array}{l}A_{\text {core }}{ }^{[g]} \\
{\left[\AA^{2}\right]}\end{array}$ & $\begin{array}{l}\mathrm{D}_{\text {cyl }}^{[\mathrm{h}]} \\
\mathrm{D}_{\mathrm{ell}}^{[\mathrm{h}]} \\
{[\AA]}\end{array}$ & $\begin{array}{l}S_{\mathrm{cyl}}^{[1]} \\
S_{\text {ell }}^{[1]} \\
{\left[\AA^{2}\right]}\end{array}$ & $\begin{array}{l}\mathrm{q}_{\mathrm{cyl}} \mathrm{l}^{0} \\
\mathrm{q}_{\mathrm{ell}}\end{array}$ \\
\hline BDTC & 70 & 3700 & 0.96 & 0.801 & 31.83 & $877.4[1]$ & 4.22 & 3.73 & 30 & 174.6 & $\begin{array}{l}14.91 \\
21.09\end{array}$ & $\begin{array}{l}19.75 \\
21.54\end{array}$ & $\begin{array}{l}0.90 \\
0.98\end{array}$ \\
\hline BDTDd & 220 & 4200 & 0.88 & 0.827 & 31.18 & $841.9[1]$ & 4.99 & 3.80 & 40 & 145.6 & $\begin{array}{l}13.62 \\
19.25\end{array}$ & $\begin{array}{l}26.68 \\
29.09\end{array}$ & $\begin{array}{l}1.09 \\
1.19\end{array}$ \\
\hline BDTDd & 150 & 4040 & 0.91 & 0.820 & 31.87 & $879.6[1]$ & 4.59 & 3.55 & 40 & 158.3 & $\begin{array}{l}14.20 \\
20.08\end{array}$ & $\begin{array}{l}25.61 \\
27.92\end{array}$ & $\begin{array}{l}1.10 \\
1.19\end{array}$ \\
\hline BDTDd & 130 & 4000 & 0.92 & 0.818 & 32.10 & $892.4[1]$ & 4.48 & 3.50 & 40 & 162.4 & $\begin{array}{l}14.38 \\
20.34\end{array}$ & $\begin{array}{l}25.31 \\
27.60\end{array}$ & $\begin{array}{l}1.10 \\
1.20\end{array}$ \\
\hline BDTDd & 110 & 3950 & 0.93 & 0.816 & 31.96 & $884.6[1]$ & 4.46 & 3.47 & 40 & 162.8 & $\begin{array}{l}14.39 \\
20.36\end{array}$ & $\begin{array}{l}25.24 \\
27.52\end{array}$ & $\begin{array}{l}1.11 \\
1.21\end{array}$ \\
\hline CDTOC & 95 & 3475 & 0.94 & 0.790 & 34.26 & $1016.5[1]$ & 3.42 & 3.53 & 0 & 213.5 & $\begin{array}{l}16.49 \\
23.31\end{array}$ & $\begin{array}{l}22.13 \\
24.13\end{array}$ & $\begin{array}{l}0.99 \\
1.08\end{array}$ \\
\hline CDTOd & 100 & 3940 & 0.92 & 0.810 & 35.89 & $1115.5[1]$ & 3.53 & 3.58 & 0 & 211.9 & $\begin{array}{l}16.43 \\
23.23\end{array}$ & $\begin{array}{l}22.78 \\
24.84\end{array}$ & $\begin{array}{l}1.01 \\
1.10\end{array}$ \\
\hline CDTOd & 150 & 4055 & 0.90 & 0.820 & 35.89 & $1115.5[1]$ & 3.63 & 3.54 & 0 & 200.8 & $\begin{array}{l}16.00 \\
22.61\end{array}$ & $\begin{array}{l}22.82 \\
24.89\end{array}$ & $\begin{array}{l}0.98 \\
1.07\end{array}$ \\
\hline CDTOe & 110 & 4425 & 0.91 & 0.830 & 37.91 & $1244.6[1]$ & 3.55 & 3.58 & 0 & 211.6 & $\begin{array}{l}16.41 \\
23.21\end{array}$ & $\begin{array}{l}22.91 \\
24.98\end{array}$ & $\begin{array}{l}1.01 \\
1.10\end{array}$ \\
\hline \multicolumn{14}{|c|}{ 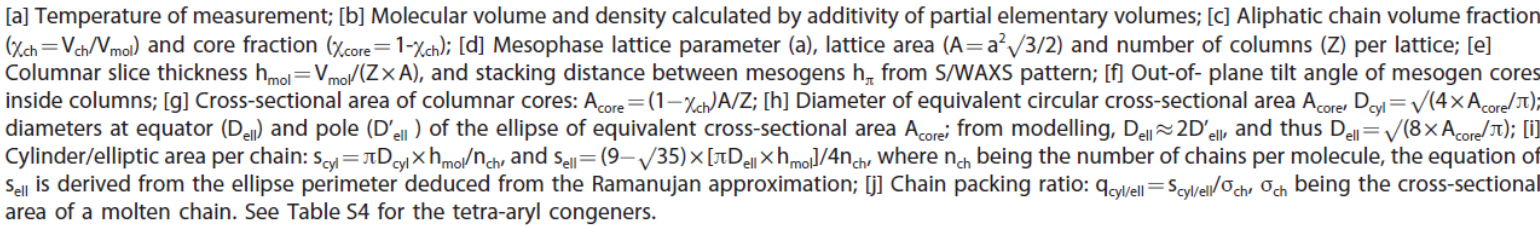 } \\
\hline
\end{tabular}

As for DTT compounds previously reported,[27] the insertion of phenylene (BDT and BDTD) or cyclopentanone (CDTO) molecular units between the two thiophene moieties confers an elliptical shape to the aromatic rigid core. The depletion of chains in the central parts of BDTD/CDTO, may foster stronger interactions between consecutive mesogens. A rough estimation deduced by molecular modelling (Figures S38-S40) gives an elliptical core aspect ratio of around 2 (i. e. ratio of the diameters at the equator and at the poles, Table 1 and Figure 5). The emergence of the hexagonal symmetry however implies that the columns must have an averaged circular cross-section area, causing a homogeneous distribution of the aliphatic chains at the periphery. Despite this structural core anisotropy, the shape of the core-to-periphery interface of the columns can be averaged to a cylinder through the continuous orientational change of the elliptical mesogens along the stacking direction, with, if applicable, some additional tilt of the cores with respect to the plane symmetry to guarantee this cylindrical symmetry, and if necessary to increase the core-chain interface.[37] This way, the space-demanding radiating alkyl chains can be distributed over the whole stack periphery. The elongated shape of the cores also implies, for identical cross-sections' areas that the contact area between cores and radiating alkyl chains is at local-range larger than the statistical cylinder area ( $s_{\text {ell }}$ versus $s_{\text {cyl }}$ in Table 1, Figure 5). The values of the molecular slice thickness, $h_{\text {mol }}$ (Table 1 ) deduced 
experimentally, confirms the necessity of a tilt for BDTc/BDTDd cores due to substantial shift from $h_{\pi}$ $\left(h_{\text {mol }}>h_{\pi}\right)$, whereas these values for compounds CDTOc-e are similar to the stacking distance $\left(h_{\text {mol }} \approx h_{\pi}\right)$, implying a quasi-non-tilted stacking of the cores along the columnar axis. For the latter compounds, the area needed by the peripheral chains is also compatible with the interface area offered by the nontilted stacked mesogens, since the ratio $\mathrm{q}_{\mathrm{cyl}}$ (Table 1 ) between required and available areas does not deviate from unity;[38] the chains are therefore fully stretched in the plane and densely packed in this case, allowing for easy orientational changes between neighbouring molecules within and between columns, which as a result equally distribute the aliphatic chains in the periphery of the columns. The slight divergence of the ratio from unity for the other derivatives is in agreement with the steric hindrance from the additional lateral chains (BDT series) or the two carbonyl groups (BDTD series), which compromise a perfect orthogonal stacking into columns in order to manage the distribution of the appending chains or carbonyl fragments evenly, respectively.[38] These models (Figure 5) are also in agreement with the relative mesophase stability (i. e. temperature range) observed in these series. As seen above, the tetraaryl precursors are also mesomorphous, although providing that the core is devoid of the two central chains as in 2. Compounds $\mathbf{3 d}$ and $\mathbf{4 c - e}$ show a Col $\mathrm{l}_{\text {hex }}$ phase but at lower temperature and over smaller ranges than their annulated congeners. Their lattice parameters (Figure 4) are slightly increased with respect to their more constrained annulated congeners due to the slight in-plane expansion of the free aryl substituents. These compounds adopt an overall circular shape with the phenyl groups lying out of plane i.e. a propeller conformation.[30,35,36] Such a flexible configuration allows a more optimum stacking by their alternated and shifted intercalation in the periphery and greater freedom in the chains' arrangement. The area needed by the peripheral chains is also compatible with the interface area offered by this type of stacking, since the ratio qcyl (Table S4) of both areas does not deviate excessively from unity. This suggests as above an almost equitable distribution of the aliphatic chains in the periphery of the columns.

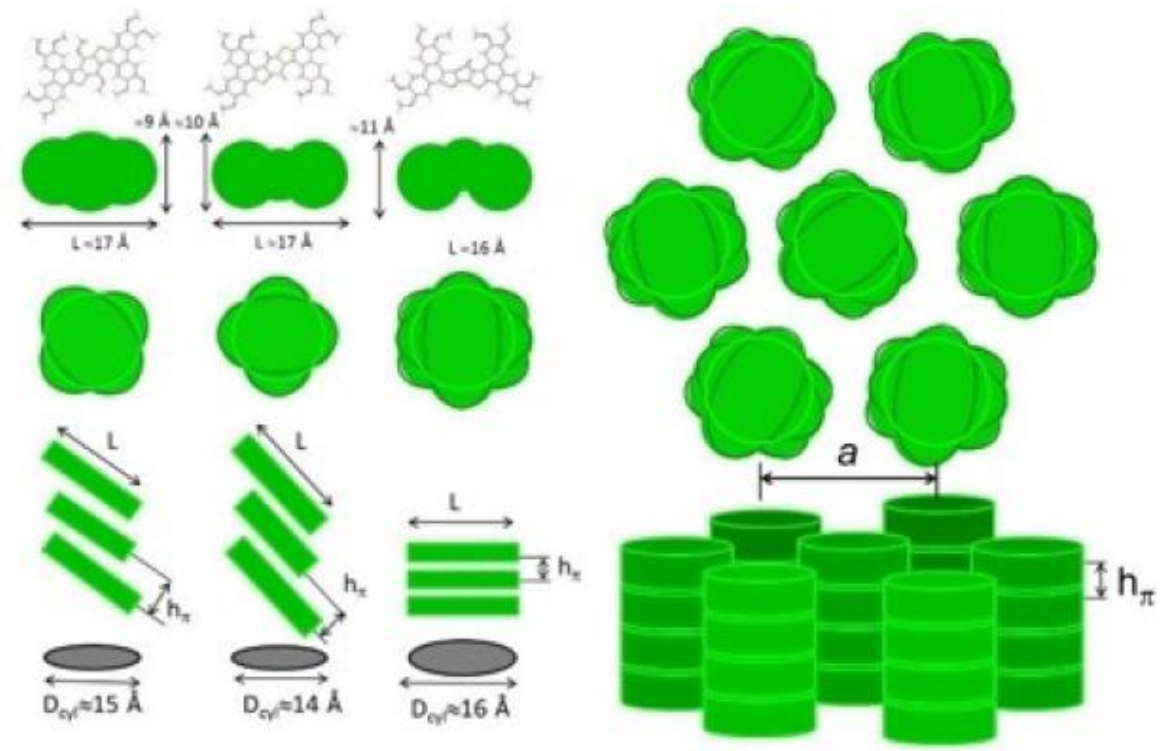

Figure 5. Schematic representation of the three butterfly-like mesogens; the elongated shape of the aromatic core roughly approximates an ellipse of aspect ratio close to 2 , offering an interface area per peripheral chain sell (bright green contour line); the continuous orientational changes of the stacked (tilted or non-tilted) cores, perpendicular to the columnar axis, distribute the space-demanding radiating alkyl chains over the whole stack periphery and design average cylindrical columns of reduced statistical interface area $s_{\text {cyl; cylindrical columns }}$ arranging in hexagonal lattices of parameter $a$ and with molecular slice thickness hmol compared to $\pi$-stacking distance, $h \pi$. 
Photophysical properties As anticipated from the presence of the thiophene central core, all the compounds exhibit strong light absorption and demonstrate also for some of them photo-induced light emission. Based on the optical absorption and emission spectra, the resulting optical HOMO-LUMO energy gaps $\left(\mathrm{E}_{\mathrm{FO}}\right)$ were calculated. The optical energy gap $\left(\mathrm{E}_{\mathrm{opt}}\right)$ was determined from the onset of the long-wavelength absorption edge ( $\lambda_{\text {onset }}$ ) from the solution UV/vis spectra. In Table 2 are summarized the optical properties of all derivatives. UV/vis absorption spectra were recorded in THF solutions with concentration of $1 \times 10^{-5} \mathrm{molL}^{-1}$ (Figures $6 \mathrm{a}$ and S5). Broad absorption bands with two distinct maxima at 293, $346 \mathrm{~nm}$ for $\mathbf{1 a}-\mathbf{2 c}$ and at 302, $382 \mathrm{~nm}$ for BDTa-c, respectively, were seen. Generally, this band can be assigned to $\pi-\pi^{*}$ transitions of the conjugated aromatic moieties. As expected, a red shift of the absorption occurred in the extended $\pi$-conjugated systems. In detail, the most prominent peak with maximum absorption is shifted by $9 \mathrm{~nm}$, from $293 \mathrm{~nm}\left(\varepsilon, 3.61 \times 10^{-4} \mathrm{M}^{-1} \mathrm{~cm}^{-1}\right)$ in 1 a to $302 \mathrm{~nm}(\varepsilon$, $\left.9.41 \times 10^{-4} \mathrm{M}^{-1} \mathrm{~cm}^{-1}\right)$ for its annulated congener BDTa, with an increasing of the absorption intensity (molar coefficient). No significant change in absorption was observed upon changing the length and number of peripheral chains and of the solvent (Figure S5).

\begin{tabular}{|c|c|c|c|c|c|c|c|}
\hline Cpds & $\begin{array}{l}\lambda_{\text {as }}[\mathrm{nm}] \\
{\left[\varepsilon, 10^{4} \times\right.} \\
\left.\mathrm{M}^{-1} \mathrm{~cm}^{-1}\right]\end{array}$ & $\begin{array}{l}\lambda_{\text {onnat }} \\
{[\mathrm{nm}]}\end{array}$ & $\begin{array}{l}E_{\text {opt }}^{|l| \mid} \\
{[\mathrm{eV}]}\end{array}$ & $\begin{array}{l}\lambda_{\mathrm{mm}}{ }^{\mathrm{B} \mid} \\
{[\mathrm{nm}]}\end{array}$ & $\begin{array}{l}\lambda_{\mathrm{mm}^{[x]}} \\
{[\mathrm{nm}]}\end{array}$ & $\begin{array}{l}\mathrm{QY}^{\text {bil }} \\
{[9 \%]}\end{array}$ & $\begin{array}{l}E_{s o}[1] \\
{[e V]}\end{array}$ \\
\hline \multirow[t]{3}{*}{$1 \mathrm{a}$} & $293[3.61]$ & 420 & 2.95 & 416 & 421 & 13.1 & - \\
\hline & $346[3.47]$ & & & 438 & 444 & & \\
\hline & $378[2.89]$ & & & 464 & 469 & & \\
\hline \multirow[t]{3}{*}{$2 b$} & $293[3.82]$ & 420 & 2.95 & 416 & 417 & 13.0 & - \\
\hline & $346[3.67]$ & & & 437 & 441 & & \\
\hline & $378[3.10]$ & & & 464 & 465 & & \\
\hline \multirow[t]{3}{*}{$2 c$} & $293[4.06]$ & 420 & 2.95 & 416 & 419 & 13.5 & 3.54 \\
\hline & $346[3.82]$ & & & 437 & 444 & & \\
\hline & $378[3.09]$ & & & 464 & 465 & & \\
\hline \multirow[t]{2}{*}{$3 d$} & 316 [4.01] & 589 & 2.11 & - & - & - & 2.26 \\
\hline & $448[0.90]$ & & & & & & \\
\hline \multirow[t]{2}{*}{$4 d$} & $299[4.13]$ & 688 & 1.80 & - & - & - & 2.42 \\
\hline & $561[0.57]$ & & & & & & \\
\hline \multirow[t]{3}{*}{ BDTa } & $302[9.41]$ & 429 & 2.89 & 421 & 436 & 2.0 & - \\
\hline & $383[5.66]$ & & & 445 & 463 & & \\
\hline & $412[3.87]$ & & & 473 & 493 & & \\
\hline \multirow[t]{3}{*}{ BDTb } & $301[9.56]$ & 429 & 2.89 & 420 & 437 & 2.5 & - \\
\hline & $382[5.68]$ & & & 445 & 484 & & \\
\hline & $411[3.85]$ & & & 473 & & & \\
\hline \multirow[t]{3}{*}{ BDTc } & 301 [10.07] & 429 & 2.89 & 420 & 429 & 2.3 & 3.40 \\
\hline & $382[6.23]$ & & & 445 & 456 & & \\
\hline & $411[4.25]$ & & & 473 & 480 & & \\
\hline \multirow[t]{3}{*}{ BDTDd } & 299 [5.92] & 692 & 1.79 & - & - & - & 2.10 \\
\hline & $372[3.11]$ & & & & & & \\
\hline & $531[1.27]$ & & & & & & \\
\hline \multirow[t]{4}{*}{ CDTOd } & $304[6.07]$ & 800 & 1.55 & - & - & - & 2.21 \\
\hline & $355[3.47]$ & & & & & & \\
\hline & $374[5.51]$ & & & & & & \\
\hline & $644[0.52]$ & & & & & & \\
\hline \multicolumn{8}{|c|}{ 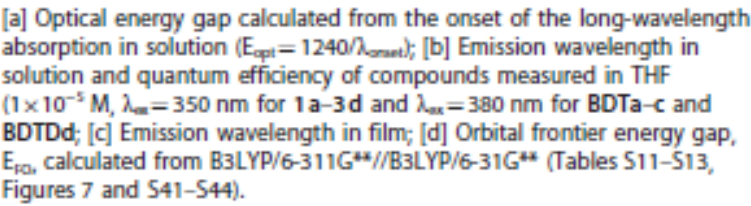 } \\
\hline
\end{tabular}
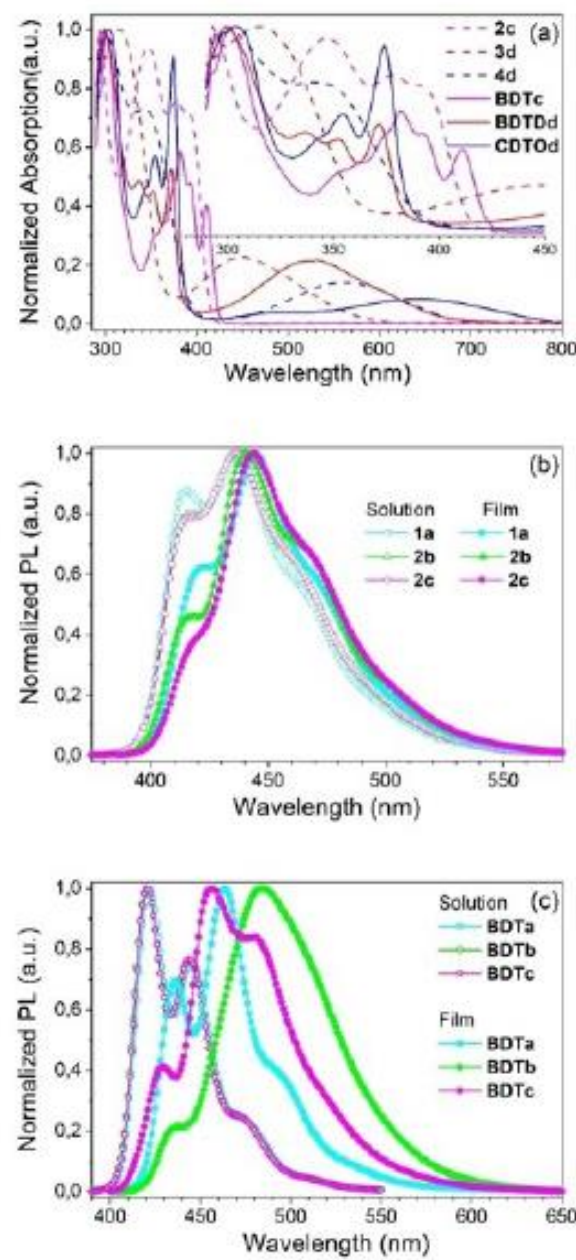

Figure 6. Absorption and photoluminescence spectra. (a): UV/vis absorption spectra of $\mathbf{2 c} / \mathbf{3 d} / \mathbf{4 d}$ and corresponding diphenanthrenes; Fluorescence emission spectra in solutions and films of (b): benzodithiophene 1a/2 b-c derivatives, $\lambda_{e x}=350 \mathrm{~nm}$; (c): and corresponding BDTa-c derivatives, $\lambda_{e x}=380 \mathrm{~nm}$. 
The absorption spectra of BDTD derivatives (3d and BDTDd) and CDTO derivatives (4d and CDTOd) exhibited the general feature consisting of one strong intense absorption band in the UV region, which is attributed to $\pi-\pi^{*}$ transitions as like the OR-substituted/S-bridged central aromatic derivatives, and a broad but less intense absorption band in the visible region. All of these derivatives could be regarded as quadrupolar donor-acceptor-donor molecules,[19a] in which BDTD/ CDTO-cores are strong electron acceptors in contrast to the electron donor character of the substituted aryl derivatives. Such systems show a moderately intense absorption band in their UV/vis spectra, which can be assigned to intramolecular charge transfer (ICT) between donor moiety and acceptor unit. Because both of the BDTD and CDTO moieties possess substantial quinoidal character within the conjugated backbone, it allowed for stable electron delocalization consistent with the broad absorption band exhibited in these derivatives. On the other hand, a significant bathochromic shift in the absorption edge was observed when the central aromatic ring substituents were changed from alkoxy group (OR) to carbonyl group $(\mathrm{C}=\mathrm{O})$. For instance, the S0-S1 transition peak shifted from $378 \mathrm{~nm}$ in $\mathbf{2 c}$ by $70 \mathrm{~nm}$ to $448 \mathrm{~nm}$ in $\mathbf{3 d}$ and by $183 \mathrm{~nm}$ to $561 \mathrm{~nm}$ in $\mathbf{4 d}$. Similar bathochromic shift of $120 \mathrm{~nm}$ and $233 \mathrm{~nm}$ were observed in the aryl fused system ( $\lambda_{\max }: 531 \mathrm{~nm}$ in BDTDd and $644 \mathrm{~nm}$ in CDTOd as compared with $411 \mathrm{~nm}$ in BDTc). Such observations can be attributed to the smaller band gap caused by the extension of the $\pi$ conjugated skeleton upon the introduction of the $\mathrm{C}=\mathrm{O}$ group, which is represented by a red shift of the maximum absorption wavelength (Figure 6).

Emission properties of $\mathbf{1} \mathbf{a} / \mathbf{2} \mathbf{b}-\mathbf{c}$ and $\mathbf{B D T a}-\mathbf{c}$ were studied both in solution and film state (Figure $\mathbf{6 b}-\mathbf{c}$ ), while a primary photoluminescent (PL) peak at $437 \mathrm{~nm}$ with two equally spaced shoulder (416 and 464 $\mathrm{nm}$ ) for $\mathbf{1 a / 2} \mathbf{b}-\mathbf{c}$ and two separated peaks ( 420 and $445 \mathrm{~nm}$ ) as well as weak shoulder at $473 \mathrm{~nm}$ for BDTa-c were observed in THF solution $\left(1 \times 10^{-5} \mathrm{M}\right)$. As for the fluorescence emission in molten film state, all derivatives but BDTb, with a disappearing shoulder at long wavelength, exhibited similar peak conditions as in solution and obvious maxima red-shifted by ca. $10 \mathrm{~nm}$ to up to $36 \mathrm{~nm}$ compared to only 4 to $7 \mathrm{~nm}$ in $1 \mathrm{a}-2 \mathrm{c}$. This result can be explained by considering the stacking motif within the aggregation process. The four aryl groups bonded on $\mathbf{1 a} \mathbf{a} \mathbf{2} \mathbf{b} \mathbf{b}-\mathbf{c}$ are more turbulent with respect to their planar core due to steric constraints, while the annulated planar molecules BDTa-c aggregate in thin film state and have stronger intermolecular interactions. Compounds $\mathbf{3 d} / \mathbf{4 d}$, BDTDd/CDTOd were however found non-emissive, as the photo-induced intramolecular electron transfer resulted in the quenching of the emission in both solutions and films.

DFT calculations Density function theory (DFT) method was used to calculate the frontier molecular orbitals (FMO) distribution, energy levels and gaps for the methoxy homologs of these $\pi$-conjugated molecular scaffolds (Figures 7 and S43-S44).

The calculated HOMO-LUMO energy levels and gaps are all distinctive. The BDT electron-rich molecule has low-lying HOMO $(-5.30 \mathrm{eV})$, and high-lying LUMO $(-1.90 \mathrm{eV})$, and a consequently wide energy gap $(3.40 \mathrm{eV})$, while the electron-deficient diketone BDTD exhibits lowered HOMO energy level $(-5.67 \mathrm{eV})$ and much lowered LUMO level $(-3.57 \mathrm{eV})$, giving a narrower energy gap of $2.10 \mathrm{eV}$. The calculated FMO of the ketone derivative CDTOd lie in between of the former ones, with a HOMO level at $-5.23 \mathrm{eV}$ and a LUMO level at $-3.02 \mathrm{eV}$, and a comparable energy gap of $2.21 \mathrm{eV}$. The DFT results agreed rather well with the measured UV-Vis absorption and photoluminescence spectra (Table 2). Compared with the tetraaryl molecules $\mathbf{2} \mathbf{c}, \mathbf{3} \mathbf{d}$ and $\mathbf{4} \mathbf{d}$, the corresponding diphenanthrenes, possessing more extended $\pi$ conjugating systems, displayed lowered LUMO and narrower energy gaps, which were evidenced by the red-shifted observed in the absorption and emission spectra. The polar molecules BDTDd and CDTOd had different HOMO/LUMO wave function distributions, implying intramolecular charge transfer (ICT) and explaining theoretically the quenching of fluorescence. At last, DFT results further predict the potential ambipolar charge carrier property of the polar compounds, as it will be discussed in TOF photoconductivity part. 


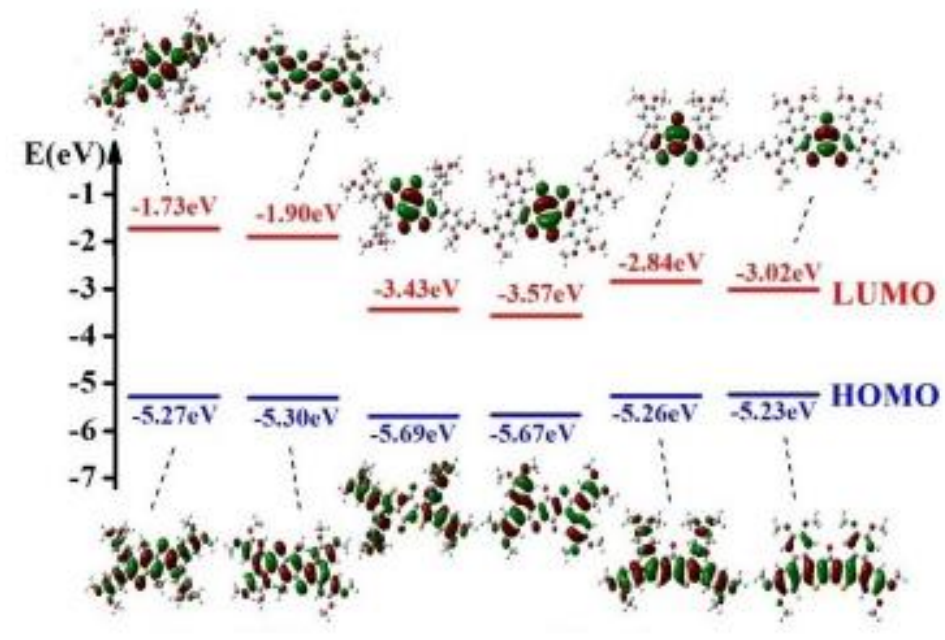

Figure 7. Comparison of frontier molecular orbitals and HOMO-LUMO, energy levels and gaps calculated for the methoxy homologs 2-OMe, BDT-OMe, 3-OMe, BDTD-OMe, 4-OMe and CDTO-OMe (from left to right).

Gelling behavior Polycyclic aromatic hydrocarbons consisting of large cores and multiple peripheral alkyl chains have strong tendency to form supramolecular aggregation or gels via $\pi-\pi$ stacking, the flexible alkyl chains not only providing van der Waals interactions to facilitate self-association but also imparting favourable solubility characteristics to control the balance between aggregation and dissolution in solution.[39] The gelling phenomenon of giant $\pi$-conjugated aromatics with long alkyl chain is an obvious demonstration of the anisotropic property of $\pi-\pi$ stacking and solubility of the alkyl part.

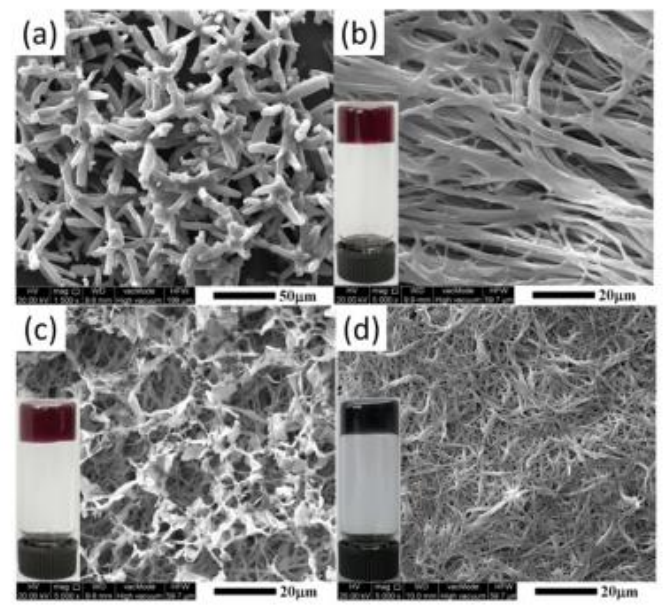

\begin{tabular}{|c|c|c|c|c|}
\hline Solvent & BDTa & BDTC & DBDTd & CDTOd \\
\hline Hexane & $\mathrm{s}$ & $\mathrm{s}$ & PS & $G(1.5) \circ$ \\
\hline Cyclohexane & $\mathrm{s}$ & $\mathrm{s}$ & $\mathrm{G}(1.0) \mathrm{t}$ & $G(1.5) \circ$ \\
\hline Toluene & $\mathrm{S}$ & $\mathrm{S}$ & $G(1.5) \circ$ & $G(1.0) \circ$ \\
\hline $\mathrm{CH}_{2} \mathrm{Cl}_{2}$ & $\mathrm{~s}$ & $\mathrm{~s}$ & PS & $G(2.0) \circ$ \\
\hline $\mathrm{CHCl}_{3}$ & $\mathrm{~s}$ & $\mathrm{~s}$ & $G(3.0) \circ$ & $G(4.5) \circ$ \\
\hline THF & $\mathrm{s}$ & $\mathrm{S}$ & $G(1.5) \circ$ & $G(1.5) \circ$ \\
\hline Ethanol & I & I & I & 1 \\
\hline Ethyl acetate & $\mathrm{s}$ & $\mathrm{s}$ & I & PS \\
\hline
\end{tabular}

[a] G, S, PS and I indicate the state of the mixture when heated, corresponding to gel, solution, poor solution and insoluble, respectively; [b] The numbers in brackets correspond to the critical gelation concentration (CGC) in $\mathrm{mg} \mathrm{mL}^{-1} ;[\mathrm{c}] \mathrm{o}$ and $\mathrm{t}$ denoted the appearance of the gel: $\mathrm{o}$, opaque gel; $\mathrm{t}$, transparent gel.

Figure 8. Scanning electronic microscopy (SEM) images of xerogels or crystals: (a), BDTc crystals in $\mathrm{CHCl}_{3} / \mathrm{EtOH}$ good/poor solvent; (b,c), BDTDd xerogels in cyclohexane and THF, respectively; (d) CDTOd xerogels in THF. Other SEM images are shown in Figure S7.

The gelation ability of these various diphenyl-fused derivatives BDTa,c, BDTDd and CDTOd was therefore evaluated in various organic solvents, polar and non-polar, protic and non-protic. A fixed amount of the sample was dissolved in different solvents by heating until complete dissolution and 
then were slowly cooled down. The formation of the organogels was confirmed by the "stable to inversion of the test tube" method (Figures 8 and S6). The results are summarized in Table 3.

Surprisingly, neither BDTa nor BDTc are able to gel any of the solvents considered, they are just highly soluble in all of the tested ones. In contrast, CDTOd exhibits good gel formation behaviour in hexane, cyclohexane, toluene, dichloromethane, trichloromethane, tetrahydrofuran. BDTDd, having a lower solubility, is only able to gel cyclohexane, toluene, trichloromethane, tetrahydrofuran, and is partially dissolved in hexane and dichloromethane. Further, we noticed that the phase transitions of the organogels were thermally reversible even after several heating and cooling cycles, while BDTDd and CDTOd formed opaque gels in various solvents (in cyclohexane BDTDd formed a transparent gel). The critical gel concentrations (CGC) were estimated for both BDTDd and CDTOd. CGC values lie in the range of 0.11 to $0.30 \mathrm{wt} \%$, indicating that they can be considered as supergelators (i.e. materials capable of gelling solvents with a concentration lesser than $1 \mathrm{wt} \%$ ).[39] In addition, these gelators exhibit a significant structure and solvent dependency. For example, the CGC value of previously reported structurally related dithienothiophene derivatives[27] in toluene was $2.5 \mathrm{mg} / \mathrm{mL}$, while those of BDTDd and CDTOd dropped to 1.5 and $1.0 \mathrm{mg} / \mathrm{mL}$, respectively. Likewise, the value of CDTOd and DTT[27] were 1.5 and $2.0 \mathrm{mg} / \mathrm{mL}$ in hexane, respectively. In the case of BDTa and BDTc, the nonformation of gel may be imparted to both the electron-rich character of the core and the presence of two alkyl chains, branched or linear, irradiating from the central core, that strongly diminish the efficiency of staking through $\pi-\pi$ interactions as well as filling the available space.

The improved gelation efficiency can be attributed to the presence of additional dipole-dipole interaction introduced by ketone group, while $\pi-\pi$ interactions remain the primary driving force to form gel. [39] Besides, the nature of the solvent also had an effect on CGC: CDTOd showed a CGC value of $4.5 \mathrm{mg} / \mathrm{mL}$ in $\mathrm{CHCl}_{3}, 2.0 \mathrm{mg} / \mathrm{mL}$ in $\mathrm{CH}_{2} \mathrm{Cl}_{2}$ and $1.5 \mathrm{mg} / \mathrm{mL}$ in THF as compared to $1.0 \mathrm{mg} / \mathrm{mL}$ in toluene. Furthermore, the CGC value of BDTDd decreased from 3.0 to 1.5 and $1.0 \mathrm{mg} / \mathrm{mL}$ in $\mathrm{CHCl}_{3}$, THF and cyclohexane, respectively, as the polarity of solvent decreased. Therefore, the strong solvent dependency of gelation may be attributed to stronger $\pi-\pi$ interactions in non-polar hydrocarbon solvent than in polar solvent, as reported in other discotic mesogens.[39] In summary, the mechanical strength of the organogels is dependent on gelator-gelator interactions: here mainly $\pi-\pi$ and dipoledipole interactions, and to a lesser extend to the gelator-solvent interactions.

To gain a direct insight into the self-assembled gel microstructures, xerogels of gelators BDTDd/CDTOd obtained from various solvents or by precipitation of the non-gelator BDTc from mixed solvents e.g. trichloromethane as the "good" solvent and ethanol as the "poor" solvent, were studied by scanning electron microscopy (SEM, Figures 8 and S7). As revealed by SEM, representative morphologies of the self-assemblies of BDTc and gelators BDTDd/CDTOd showed densely packed 3D networks, which resulted in the solvent immobilization. [40] Specifically, xerogels of BDTDd, obtained from cyclohexane, formed a closely packed 3D networks composed of wide, straight fibrous bundles (Figure 8b). A similar structure but composed of thinner interlocked and more flexible ribbons was observed in the case of CDTOd in THF and toluene (Figures $8 \mathrm{~d}$ and S7h). Besides, a xerogel morphology with two interlocked 3D structures was observed for BDTDd in THF (Figure 8c) and in toluene (Figure S7c). However, the self-assembled morphology of BDTc aggregated in a mixed solvent containing good/poor solvents exhibited coarse, short fibrillary rods (Figure 8a), in which the structure with open features cannot form rings or holes leading to difficult solvent fixation, thereby in agreement with the non-gelling behaviour of BDTc. Similar fibrous morphologies were revealed for CDTOd in hexane, dichloromethane and chloroform (Figure S7).

Photoconductivity Self-organized discotic columnar nanostructures consisting of $\pi$-extended polycyclic aromatic hydrocarbons can be envisaged as potentially microscopic supramolecular cables 
for charge carrier hopping highways. Transient photocurrent time-of-flight (TOF) technique is a unique, accurate, direct, and simple method to measure charge carrier mobility rate of organic semiconductors with a very long charge hopping pathway.[41] Further, by this method, both electron and hole mobility rates can be measured independently; the charge carriers drift a distance of 15 to $20 \mu \mathrm{m}$ along the $\pi$ $\pi$ overlapping columns stacked by thousands of discotic molecules, very similar to their configurations in electronic devices.

We have investigated the photoconducting properties of three representatives of these butterflyshaped fused-thiophene columnar mesogens by using the aforementioned TOF technique, and the results are showed in Figures 9 and 10, and in more detail in supplementary information (Figures S8S16 and Table S5-S10). The transient photo current decay curves are all in good shape and nondispersive (Figure 9), demonstrating the high purity of these molecular semiconductors and their excellent homeotropic alignment behaviour and thermal stability in ITO cells.

The isotropic liquid state of $\mathbf{4 d}$ at $110^{\circ} \mathrm{C}$ displays low hole mobility, i.e. $3.1 \times 10^{-5} \mathrm{~cm}^{-2} \mathrm{~V}^{-1} \mathrm{~s}^{-1}$ (Figure 10a). On cooling, passing in the second liquid ( $I^{\prime}$, see above), the hole mobility substantially increases by a factor of 5 to $1.7 \times 10^{-4} \mathrm{~cm}^{-2} \mathrm{~V}^{-1} \mathrm{~s}^{-1}$. Then, it increases to $7.9-4 \times 10^{-4} \mathrm{~cm}^{-2} \mathrm{~V}^{-1} \mathrm{~s}^{-1}$ in the Col hex phase, corresponding to the same range of the well-known triphenylene discogens.[42] This rather low value reflects the formation of relatively short-range ordered $1 \mathrm{D} \pi$-stacked nanostructures in the Col hex phase, as confirmed by S/WAXS (weak $h_{\pi}$ signal, Figure 54 ). Of interest, the photoconducting mobility of $\mathbf{4 d}$ was completely reversible in successive heating and cooling runs, demonstrating that this butterfly-shaped cyclopentadithiophen-4-one core is a good semiconducting columnar mesogen. As expected, the $\pi$-extended annulated congener CDTOd displays higher hole mobility rate than $\mathbf{4 d}$, in the interval $1.5-2.1 \times 10^{-3} \mathrm{~cm}^{-2} \mathrm{~V}^{-1} \mathrm{~s}^{-1}$ over the entire mesomorphic range in the cooling cycle (Figure 10b). Below $90^{\circ} \mathrm{C}$, the sample starts to crystallize in the LC cell (Figure S11), however the detected hole transport value exhibits some increase. This was attributed to the formation of poly-crystalline domains at the initial crystallizing with close intermolecular $\pi-\pi$ stacking and slow molecular dynamics, therefore increasing mobility.[43] Further, the cooling run curve shows a slightly higher hole mobility than during the heating run (Figure S12).

The other $\pi$-extended mesogen, BDTDd, exhibits even higher hole as well as electron mobility rates, with $\mu_{\mathrm{h}}=4.0 \times 10^{-3} \mathrm{~cm}^{-2} \mathrm{~V}^{-1} \mathrm{~s}^{-1}$ and $\mu_{\mathrm{e}}=5.1 \times 10^{-3} \mathrm{~cm}^{-2} \mathrm{~V}^{-1} \mathrm{~s}^{-1}$ at $220^{\circ} \mathrm{C}$, respectively (Figure $10 \mathrm{c}$ ). The electron transport behaviour exhibits a stable value of $(5.1-6.6) \times 10^{-3} \mathrm{~cm}^{-2} \mathrm{~V}^{-1} \mathrm{~s}^{-1}$ between $110-$ $220^{\circ} \mathrm{C}$, while the hole mobility rate $\mu_{\mathrm{h}}$ lies in the range of $4.0-4.5 \times 10^{-3} \mathrm{~cm}^{-2} \mathrm{~V}^{-1} \mathrm{~s}^{-1}$, before declining to $2.2 \times 10^{-3} \mathrm{~cm}^{-2} \mathrm{~V}^{-1} \mathrm{~s}^{-1}$ below $160^{\circ} \mathrm{C}$. The charge mobility of BDTDd in the Col hex mesophase reveals an important feature: both electrons and holes are transported by these materials, with $\mu_{\mathrm{e}}$ higher than $\mu_{\mathrm{h}}$. Therefore, the annulated $\pi$-extended benzodithiophene-4,8-dione core can be considered as an ambipolar mesogenic semiconductor. It is noteworthy that such high ambipolar TOF drift mobility is uncommon in dynamic columnar mesophases.

In summary, these novel butterfly-shaped fused-thiophene columnar mesogens with polar cores (BDTD and CDTO) show outstanding charge carrier transport properties largely due to their larger $\pi$ electron systems. The results can be interpreted by the Marcus theory: larger $\pi$-conjugated aromatics possess lower reorganization energies and higher electronic transfer integrals and therefore cause higher rates of charge hopping.[44] The trend observed is in good agreement with the stacking values measured by S/WAXS ( $h_{\pi}$, Figure S4), whose most intense signal, which indicates a regular and longrange stacking, is observed for BDTDd, whereas it is weaker, and thus corresponds to a shorter stacking range for CDTOd, and almost imperceptible for $\mathbf{4 d}$. Unfortunately, compounds with the electron-rich BDT core did not display satisfactory photocurrent decay curves for the drift time readout, the laser- 
induced photo-oxidation of the aromatic core might cause the failure of TOF measurement for this molecule.
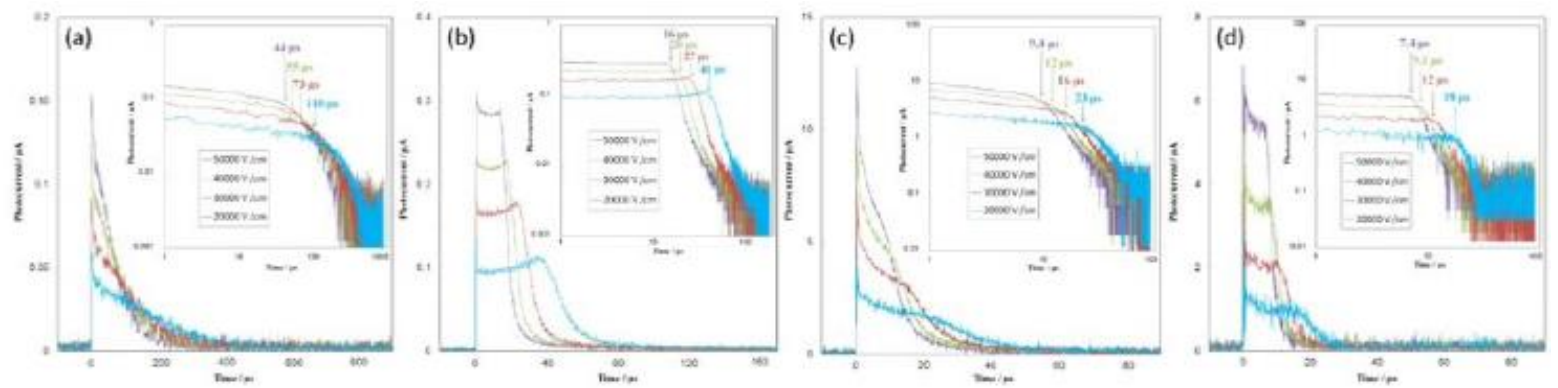

Figure 9. Transient photocurrent decay curves measured at various electric field of $(2-5) \times 10^{4} \mathrm{Vcm}^{-1}$ on cooling. (a): hole, $\mathbf{4 d}$ at $70^{\circ} \mathrm{C}$, LC cell $=17.0 \mu \mathrm{m}$; (b): hole, CDTOd at $180^{\circ} \mathrm{C}$, LC cell=16.4 $\mu \mathrm{m}$; (c): hole, BDTDd at $220^{\circ} \mathrm{C}$; (d): electron, BDTDd at $220^{\circ} \mathrm{C}$, LC cell $=18.6 \mu \mathrm{m}$. The insets show log-log plot and thetransit times were labelled.
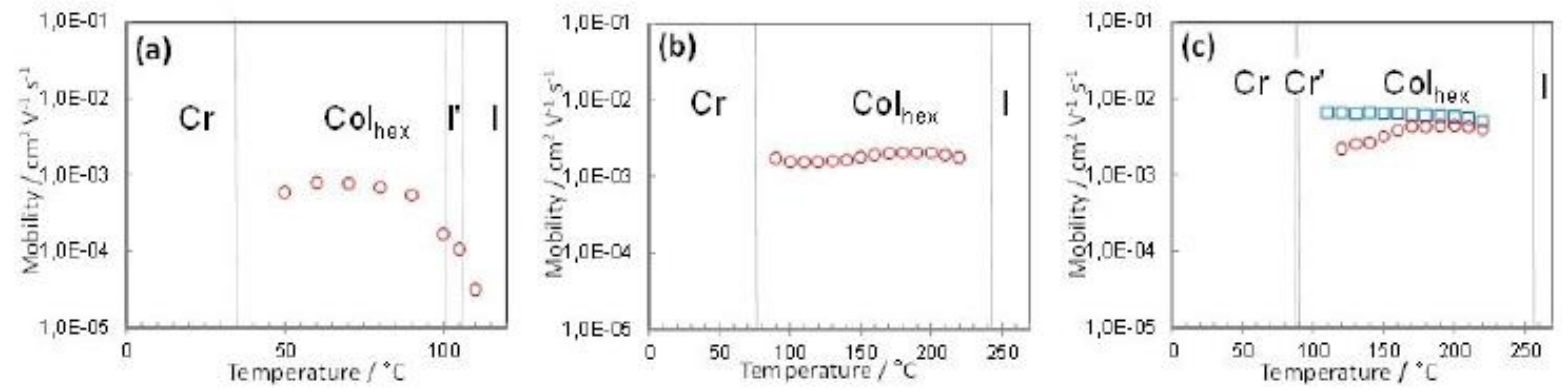

Figure 10. Temperature dependence of charge carrier mobility. (a) 4d, (b) CDTOd and (c) BDTDd on cooling run $\left(\square, \mu_{\mathrm{e}} ; \mathrm{O}, \mu_{\mathrm{h}}\right)$. DSC determined transition temperatures and corresponding phase states were denoted by straight lines (see Table S2).

Usually, three techniques are applied for the measurements of charge carrier mobility $(\mu)$ in columnar LC materials: pulse-radiolysis/flash photolysis time-resolved microwave conductivity (PR/FP-TRMC), time-of-flight photoconductivity, and space-charge limited conductivity (SCLC).[6] SCLC is very sensitive to ionic impurities of the sample-cell interface and to the history of sample thermal and electrical-field annealing, and the measured conduction from the I/V curve of a same sample may surprisingly vary by 5 to 6 orders of magnitude. [6] The TRMC technique measures the short-range, ideal charge transportation of LC samples, usually yielding high $\mu$ values. On the other hand, TOF technique measures the long-range $(10-20 \mu \mathrm{m})$ charge carrier drift mobility, which is sensitive to ionic impurities and sample alignment in LC cells. Thus, from the above, comparison of LC conducting values measured from these different techniques may not be rational nor appropriate.

In this context, the results obtained here compared quite well with those of other columnar LC thiophene derivatives reported in the literature, and thus are quite relevant. Indeed, one of the highest TOF mobility was reported for a thiophene-fused phthalocyanine-Zn complex $\left(10^{-2} \mathrm{~cm}^{-2} \mathrm{~V}^{-1} \mathrm{~s}^{-1}\right),[16]$ whereas a X-shaped pyrene-oligothiophenes[45] showed mobility in the range from $10^{-4}$ to $10^{-5} \mathrm{~cm}^{-2} \mathrm{~V}^{-1} \mathrm{~s}^{-1}$, but could be largely improved to $10^{-3} \mathrm{~cm}^{-2} \mathrm{~V}^{-1} \mathrm{~s}^{-1}$ when mixed in a physical gel blend. Let us as well mention some ambipolar octupolar $\pi$-conjugated columnar LCs with a mobility in the range $10^{-2}-10^{-3} \mathrm{~cm}^{-2} \mathrm{~V}^{-1} \mathrm{~s}^{-1}$.[19] For comparison, with PR-TRMC technique, a propeller-shaped fused 
oligothiophene columnar mesogen displayed a short-range mobility of $0.18 \mathrm{~cm}^{-2} \mathrm{~V}^{-1} \mathrm{~s}^{-1}$, [30] while its long-range TOF mobility was $0.02 \mathrm{~cm}^{-2} \mathrm{~V}^{-1} \mathrm{~s}^{-1}$, one order of magnitude lowered. Similarly, an $\mathrm{H}$-bonded benzotristhiophene derivative was reported to exhibit a mobility of $0.02 \mathrm{~cm}^{-2} \mathrm{~V}^{-1} \mathrm{~s}^{-1}$, while TOF mobility was found in the range of $10^{-3} \mathrm{~cm}^{-2} \mathrm{~V}^{-1} \mathrm{~s}^{-1}$.[46]

The most important factors in determining conductivity of LC semiconductors remain thus essentially the extension of their $\pi$-conjugated aromatic core and the order degree of stacking in the selforganized mesophases in order to maximize orbital overlaps. Columnar mesogens with enlarged $\pi-$ conjugating cores, such as hexabenzocoronenes,[47] phthalocyanines,[48] and dibenzocoronene diimides,[49] indeed display very high conductivities. These new butterfly-shaped thiophene-fused discogens, as well as some reported previously by us,[25-27] stand out therefore as effective concurrents, and can be foreseen as promising candidates for future applications in thin film electronic devices.

\section{Conclusions}

We have demonstrated an efficient synthetic process to access new thiophene-fused butterfly-shaped columnar liquid crystals from accessible starting materials. The tandem of reactions used, SuzukiMiyaura cross-coupling and intramolecular Scholl aromatic oxidative cyclo-dehydrogenation, respectively, proceeded in high overall yields. As expected, the electronic and stereo effects of the molecules have significant impact on their self-organizational behaviours, photophysical properties, gelation and semiconducting properties. For the tetraphenyl-substituted thiophene-containing aromatic hydrocarbons, electron-deficient (ketone $\mathbf{4} \mathbf{d}$ and quinone $\mathbf{3 d}$ ) systems exhibit advantageous effect on the formation and stabilization of Colnex mesophases by enhanced intermolecular interactions, while the electron-rich systems ( 1 and 2 ) with 10 or 12 alkyl chains do not show any mesomorphism. The intramolecular oxidative aromatic cyclization permitted the extension and hardening of the $\pi$-conjugated systems by annulating the peripheral phenyls, therefore affording materials showing broader $\mathrm{Col}_{\text {hex }}$ mesophases and higher phase transition temperatures. The electronwithdrawing ketone and diketone (quinone) functional groups separate the molecules into electrondonating and electron-accepting segments. Thus, the molecules based on CDTO and BDTD display the classical intramolecular charge transfer (ICT) UV/vis absorption band, which consequently quenches the fluorescence emission, while molecules based on BDT (and the previously reported DTT) exhibit blue light fluorescence emission in both solutions and films. On the other hand, the latter display enhanced solubility thus failed to gel any organic solvents, whereas the electron-deficient molecules with less alkoxy chains but stronger $\pi-\pi$ intermolecular interactions were found to be supergelators. Finally, the charges transport mobility in their columnar mesophases was investigated by TOF transient photocurrent measurement. The electron-deficient molecular centres greatly enhance the n-type characteristic and promote strong stabilization of the Col ${ }_{\text {hex }}$ mesophase, thereby providing efficient 1D electron-transporting channels with relatively important charge carrier mobility values $\left(\mu_{\mathrm{h}}\right.$ of $4.5 \times 10^{-3} \mathrm{~cm}^{-2} \mathrm{~V}^{-1} \mathrm{~s}^{-1}$ and $\mu_{\mathrm{e}}$ of $6.6 \times 10^{-3} \mathrm{~cm}^{-2} \mathrm{~V}^{-1} \mathrm{~s}^{-1}$ for the ambipolar BDTDd and $\mu_{\mathrm{h}}$ of $2.1 \times 10^{-3} \mathrm{~cm}^{-2} \mathrm{~V}^{-1} \mathrm{~s}^{-1}$ for CDTOd). We believe that more exciting mesogenic semiconducting materials, with improved mobility values, may be easily attainable by this highly reliable synthetic methodology from a wide range of available carbon- and heteroatom-based extended $\pi$-conjugating molecular scaffolds in the near future. This should allow the exploration of new molecular designs and paradigms of practical interest for the study and elaboration of various types of organic electronic devices. 


\section{Experimental Section}

Experimental methods, synthesis and characterization, TGA, POM, DSC, SAXS, TOF, MD, DFT, ${ }^{1} \mathrm{H}$ and ${ }^{13} \mathrm{C}$ NMR, HRMS are given in the supporting information. Supporting information for this article is available on the WWW under https://doi.org/10.1002/asia.202100173

\section{Author Information}

[a] T. Ma, Y.-J. Zhong, H.-F. Wang, Prof. Dr. K.-Q. Zhao, Prof. B.-Q. Wang, Prof. P. Hu College of Chemistry and Materials Science Sichuan Normal University Chengdu 610066 (P. R. China) E-mail: kqzhao@sicnu.edu.cn

[b] Dr. H. Monobe Nanomaterials Research Institute National Institute of Advanced Industrial Science and Technology (AIST) Ikeda, Osaka 563-8577 (Japan) E-mail: monobe-hirosato@aist.go.jp

[c] Dr. B. Donnio Institut de Physique et Chimie des Matériaux de Strasbourg (IPCMS) CNRS-Université de Strasbourg (UMR 7504) 67034 Strasbourg (France) E-mail: bertrand.donnio@ipcms.unistra.fr

\section{Author Contribution}

The manuscript was written through contributions of all authors. All authors have given approval to the final version of the manuscript.

\section{Acknowledgement}

This research was financially supported by the National Natural Science Foundation of China (NSFC, Fund numbers: 21772135, 51773140, 51973135). BD thanks the CNRS and University of Strasbourg for support.

\section{Conflict of Interest}

The authors declare no conflict of interest.

Keywords: Mesogen · Columnar · Luminescence $\cdot$ Semiconductor $\cdot$ Gel

\section{References}

[1] C. Wang, H. Dong, W. Hu, Y. Liu, D. Zhu, Chem. Rev. 2012, 112, 2208- 2267.

[2] N. Miyaura, A. Suzuki, Chem. Rev. 1995, 95, 2457-2483.

[3] M. Grzybowski, B. Sadowski, H. Butenschön, D. T. Gryko, Angew. Chem. 2020, 132, 3020-3050; Angew. Chem. Int. Ed. 2020, 59, 2998-3027.

[4] J. Wu, W. Pisula, K. Mullen, Chem. Rev. 2007, 107, 718-747. 
[5] M. Stępien, E. Gonka, M. Żyła, N. Sprutta, Chem. Rev. 2017, 117, 3479- 3716.

[6] a) R. J. Bushby, S. M. Kelly, M. O'Neill, in Liquid crystalline semiconductors: materials, properties and applications, Springer, Dordrecht Heidelberg New York London, 2013; b) A. Pron, P. Gawrys, M. Zagorska, D. Djurado, R. Demadrille, Chem. Soc. Rev. 2010, 39, 2577-2632.

[7] T. Kato, M. Yoshio, T. Ichikawa, B. Soberates, H. Ohno, M. Funahashi, Nat. Rev. Mater. 2017, 2, 17001.

[8] T. Wöhrle, I. Wurzbach, J. Kirres, A. Kostidou, N. Kapernaum, J. Litterscheidt, J. C. Haenle, P. Staffeld, A. Baro, F. Giesselmann, S. Laschat, Chem. Rev. 2016, 116, 1139-1241.

[9] S. Sergeyev, W. Pisula, Y. H. Geerts, Chem. Soc. Rev. 2007, 36, 1902-1929.

[10] B. R. Kaafarani, Chem. Mater. 2011, 23, 378-396.

[11] M. O’Neill, S. M. Kelly, Adv. Mater. 2011, 23, 566-584.

[12] L. Schmidt-Mende, A. Fechtenkotter, K. Mullen, E. Moons, R. H. Friend, J. D. MacKenzie, Science 2001, 293, 1119-1122.

[13] S. Kumar, Liq. Cryst. 2004, 31, 1037-1059.

[14] X. Feng, W. Pisula, K. Mullen, Pure Appl. Chem. 2009, 81, 2203-2224.

[15] H. Eichhorn, J. Porph. Phthal. 2000, 4, 88-102.

[16] H. Suzuki, K. Kawano, K. Ohta, Y. Shimizu, N. Kobayashi, M. Kimura, ChemistryOpen 2016, 5, 150156.

[17] V. Percec, M. Glodde, T. K. Bera, Y. Miura, I. Shiyanovskaya, K. D. Singer, V. S. K. Balagurusamy, P. A. Heiney, I. Schnell, A. Rapp, H.-W. Spiess, S. D. Hudsonk, H. Duank, Nature 2002, 419, 384-387.

[18] H.-T. Nguyen, C. Destrade, J. Malthête, Adv. Mater. 1997, 9, 375-388.

[19] a) T. Yasuda, T. Shimizu, F. Liu, G. Ungar, T. Kato, J. Am. Chem. Soc. 2011, 133, 13437-13444; b) M. Lehmann, Top. Curr. Chem. 2012, 318, 193-224; c) N. Tober, J. Winter, M. Jochem, M. Lehmann, H. Detert, Eur. J. Org. Chem. 2021, 2021, 798-809; d) T. Kushida, A. Shuto, M. Yoshio, T. Kato, S. Yamaguchi, Angew. Chem. 2015, 127, 7026-7029; Angew. Chem. Int. Ed. 2015, 54, 6922-6925.

[20] a) R. A. Reddy, C. Tschierske, J. Mater. Chem. 2006, 16, 907-961; b) H. Takezoe, K. Kishikawa, E. Gorecka, J. Mater. Chem. 2006,16, 2412-2416.

[21] A. M. van de Craats, J. M. Warman, Adv. Mater. 2001, 13, 130-133.

[22] T. Yasuda, H. Ooi, J. Morita, Y. Akama, K. Minoura, M. Funahashi, T. Shimomura, T. Kato, Adv. Funct. Mater. 2009, 19, 411-419.

[23] K. Q. Zhao, C. Chen, H. Monobe, P. Hu, B. Q. Wang, Y. Shimizu, Chem. Commun. 2011, 47, 62906292.

[24] Y. Yang, H. Wang, H. F. Wang, C. X. Liu, K. Q. Zhao, B. Q. Wang, P. Hu, H. Monobe, B. Heinrich, B. Donnio, Cryst. Growth Des. 2018, 18, 4296-4305.

[25] K. C. Zhao, J. Q. Du, H. F. Wang, K. Q. Zhao, P. Hu, B. Q. Wang, H. Monobe, B. Henrich, B. Donnio, Chem. Asian J. 2019, 14, 462-470. 
[26] C. X. Liu, H. Wang, J. Q. Du, K. Q. Zhao, P. Hu, B. Q. Wang, H. Monobe, B. Henrich, B. Donnio, J. Mater. Chem. C. 2018, 6, 4471-4478.

[27] T. Ma, H. F. Wang, K. Q. Zhao, B. Q. Wang, P. Hu, H. Monobe, B. Heinrich, B. Donnio, ChemPlusChem 2019, 84, 1439-1448.

[28] A. Mishra, C. Q. Ma, P. Bäuerle, Chem. Rev. 2009, 109, 1141-1276.

[29] M. E. Cinar, T. Ozturk, Chem. Rev. 2015, 115, 3036-3140.

[30] a) L. Chen, S. R. Puniredd, Y.-Z. Tan, M. Baumgarten, U. Zschieschang, V. Enkelmann, W. Pisula, X. Feng, H. Klauk, K. Müllen, J. Am. Chem. Soc. 2012, 134, 17869-17872; b) Q. Xiao, T. Sakurai, T. Fukino, K. Akaike, Y. Honsho, A. Saeki, S. Seki, K. Kato, M. Takata, T. Aida, J. Am. Chem. Soc. 2013, 135, 1826818271; c) Y. Li, A. Concellón, C.-J. Lin, N. A. Romero, S. Lin, T. M. Swager, Chem. Sci. 2020, 11, 46954701.

[31] K. Q. Zhao, M. Jing, L. L. An, J. Q. Du, Y. H. Wang, P. Hu, B. Q. Wang, H. Monobe, B. Heinrich, B. Donnio, J. Mater. Chem. C. 2017, 5, 669-682.

[32] J. Luo, B. Zhao, J. Shao, K. I. Lim, H. S. O. Chan, C. Chi, J. Mater. Chem. 2009, 19, 8327-8334.

[33] H. Taing, A. M. Cassar, M. U. Ocheje, S. Rondeau-Gagné, T. H. El-Assaad, C. A. Sharabati, B. R. Kaafarani, S. H. Eichhorn, ChemPlusChem 2019, 84, 103-106.

[34] K. Q. Zhao, J. Q. Du, X. H. Long, M. Jing, B. Q. Wang, P. Hu, H. Monobe, B. Henrich, B. Donnio, Dyes Pigm. 2017, 143, 252-260.

[35] L. X. Guo, Y. B. Xing, M. Wang, Y. Sun, X. Q. Zhang, B. P. Lin, H. Yang, J. Mater. Chem. C. 2019, 7, 4828-4837.

[36] I. Bala, J. De, S. P. Gupta, H. Singh, U. K. Pandey, S. K. Pal, Chem. Commun. 2020, 56, 5629-5632.

[37] B. Donnio, B. Heinrich, H. Allouchi, J. Kain, S. Diele, D. Guillon, D. W. Bruce, J. Am. Chem. Soc. 2004, 126, 15258-15268.

[38] D. Myśliwiec, B. Donnio, P. J. Chmielewski, B. Heinrich, M. Stępień, J. Am. Chem. Soc. 2012, 134, 4822-4833.

[39] a) S. S. Babu, V. K. Praveen, A. Ajayaghosh, Chem. Rev. 2014, 114, 1973-2129; b) Y. Sun, Y. Wang, M. Wu, W. Yuan, Y. Chen, Chem. Asian J. 2017, 12, 52-59; c) H. Wang, Y. Han, W. Yuan, M. Wu, Y. Chen, Chem. Asian J. 2018, 13, 1173-1179.

[40] C. Yao, Q. Lu, X. Wang, F. Wang, J. Phys. Chem. B. 2014, 118, 4661-4668.

[41] Y. Hirai, H. Monobe, N. Mizoshita, M. Moriyama, K. Hanabusa, Y. Shimizu, T. Kato, Adv. Funct. Mater. 2008, 18, 1668-1675.

[42] H. Monobe, S. Okamoto, H. Enomoto, Y. Shimizu, Jpn. J. Appl. Phys. 2010, 49, 01AF04-1-4.

[43] K. Q. Zhao, L. L. An, X. B. Zhang, W. H. Yu, P. Hu, B. Q. Wang, J. Xu, Q. D. Zeng, H. Monobe, Y. Shimizu, B. Heinrich, B. Donnio, Chem. Eur. J. 2015, 21, 10379-10390.

[44] R. A. Marcus, Angew. Chem. 1993, 105, 1161-1172; Angew. Chem. Int. Ed. Engl. 1993, 32, 11111121.

[45] K. Ping Gan, M. Yoshio, T. Kato, J. Mater. Chem. C 2016, 4, 5073-5080. 
[46] A. Demenev, S. H. Eichhorn, T. Taerum, D. F. Perepichka, S. Patwardhan, F. C. Grozema, L. D. A. Siebbeles, R. Klenkler, Chem. Mater. 2010, 22, 1420-1428.

[47] M. Kastler, F. Laquai, K. Müllen, G. Wegner, Appl. Phys. Lett. 2006, 89, 252103.

[48] M. Ozaki, M. Yoneya, Y. Shimizu, A. Fujii, Liq. Cryst. 2018, 45, 2367-2389.

[49] J. Pu, T. Yang, Y. Wang, Q. Zhu, M. Yang, C. Liu, W. Wang, Liq. Cryst. 2020, 47, 291-300. 